Article

\title{
Study of the Effect of Nanoparticles and Surface Morphology on Reverse Osmosis and Nanofiltration Membrane Productivity
}

\section{Yuming Fang and Steven J. Duranceau *}

Department of Civil, Environmental and Construction Engineering, University of Central Florida, P.O. Box 162450, Orlando, FL 32816-2450, USA; E-Mail: yuming_fang@knights.ucf.edu

* Author to whom correspondence should be addressed; E-Mail: steven.duranceau@ucf.edu; Tel.: +1-407-823-1440; Fax: +1-407-823-3315.

Received: 3 June 2013; in revised form: 24 July 2013 / Accepted: 6 August 2013 /

Published: 15 August 2013

\begin{abstract}
To evaluate the significance of reverse osmosis (RO) and nanofiltration (NF) surface morphology on membrane performance, productivity experiments were conducted using flat-sheet membranes and three different nanoparticles, which included $\mathrm{SiO}_{2}, \mathrm{TiO}_{2}$ and $\mathrm{CeO}_{2}$. In this study, the productivity rate was markedly influenced by membrane surface morphology. Atomic force microscopy (AFM) analysis of membrane surfaces revealed that the higher productivity decline rates associated with polyamide RO membranes as compared to that of a cellulose acetate NF membrane was due to the inherent ridge-and-valley morphology of the active layer. The unique polyamide active layer morphology was directly related to the surface roughness, and was found to contribute to particle accumulation in the valleys causing a higher flux decline than in smoother membranes. Extended RO productivity experiments using laboratory grade water and diluted pretreated seawater were conducted to compare the effect that different nanoparticles had on membrane active layers. Membrane flux decline was not affected by particle type when the feed water was laboratory grade water. On the other hand, membrane productivity was affected by particle type when pretreated diluted seawater served as feed water. It was found that $\mathrm{CeO}_{2}$ addition resulted in the least observable flux decline, followed by $\mathrm{SiO}_{2}$ and $\mathrm{TiO}_{2}$. A productivity simulation was conducted by fitting the monitored flux data into a cake growth rate model, where the model was modified using a finite difference method to incorporate surface thickness variation into the analysis. The ratio of cake growth term $\left(k_{1}\right)$ and particle back diffusion term $\left(k_{2}\right)$ was compared in between different RO and NF membranes. Results indicated that $k_{2}$ was less significant for surfaces that exhibited a higher roughness. It was concluded that the valley areas of thin-film
\end{abstract}


membrane surfaces have the ability to capture particles, limiting particle back diffusion.

Keywords: productivity; nanoparticles; reverse osmosis; nanofiltration; cake growth model

\section{Symbols and Abbreviations}

\begin{tabular}{|c|c|}
\hline RO & reverse osmosis \\
\hline NF & nanofiltration \\
\hline AFM & atomic force microscopy \\
\hline TMP & trans-membrane pressure \\
\hline RMS & root mean square \\
\hline$n$ & amount of uniform slice for channel discretization \\
\hline$\Delta p$ & transmembrane pressure, $\mathrm{psi}$ \\
\hline$P_{f}$ & feed pressure, psi \\
\hline$P_{c}$ & concentrate pressure, psi \\
\hline$\Delta \pi, \Delta \pi_{\mathrm{m}}^{*}$ & osmotic pressure, psi \\
\hline$Q_{f}$ & feed flow, $\mathrm{m}^{3} / \mathrm{s}$ \\
\hline$Q_{c}$ & concentration flow, $\mathrm{m}^{3} / \mathrm{s}$ \\
\hline$Q_{p i}$ & permeate flow, $\mathrm{m}^{3} / \mathrm{s}$ \\
\hline$Q_{i}$ & flow in the membrane channel, $\mathrm{m}^{3} / \mathrm{s}$ \\
\hline$k_{m}, k_{c}, k_{p}$ & resistance coefficient for membrane, cake layer, and pore constriction \\
\hline$\mu$ & dynamic viscosity \\
\hline$F_{w i}$ & solvent permeate flux, gal/sfd \\
\hline$J_{i}$ & solute permeate flux, mg/sfd \\
\hline$k_{w i}$ & solvent mass transfer coefficient, m/s-psi \\
\hline$\theta_{w i}$ & empirical coefficient \\
\hline$\delta_{i}$ & overall membrane thickness, $\mathrm{m}$ \\
\hline$\delta_{m}$ & clean membrane thickness, $\mathrm{m}$ \\
\hline$\delta_{c}$ & cake thickness, $\mathrm{m}$ \\
\hline$k_{1}$ & cake growth term \\
\hline$k_{2}$ & particle back diffusion term \\
\hline$d t$ & time interval, $\min$ \\
\hline$W$ & membrane channel width, $\mathrm{m}$ \\
\hline$H$ & membrane channel height, $\mathrm{m}$ \\
\hline$L$ & membrane channel length, $\mathrm{m}$ \\
\hline$\rho$ & density of water, $\mathrm{kg} / \mathrm{m}^{3}$ \\
\hline$v_{i}$ & cross flow velocity, $\mathrm{m} / \mathrm{s}$ \\
\hline$k$ & friction coefficient \\
\hline
\end{tabular}




\section{Introduction}

In $\mathrm{RO}$ and NF membrane treatment processes, fouling is one of the major issues related to the deterioration in membrane performance. Efforts have been made to reduce membrane fouling by improving membrane properties, optimize operational conditions and advanced pretreatment of the feed water, however, fouling is still inevitable [1-3]. Colloidal fouling of membranes is caused by different mechanisms. For RO, NF, and perhaps some tight UF membranes, colloidal fouling is caused by the particles accumulating on the membrane surface to develop a so-called cake layer. This cake layer provides an additional hydraulic resistance to water permeating through the membrane, therefore reducing the water flux. For MF and UF membranes, pore plugging is another factor that causes membrane fouling besides the particle accumulation on the surface. The extent of pore plugging and cake formation depends on the relative size of the particles compared to the membrane pores sizes [4]. Particulate fouling has been shown to relate to the membrane surface roughness in RO and NF membrane processes in bench scale experiments [5-7]. Depending on the particle's size, density, and membrane surface roughness, fouling may occur due to accumulation of particles on the membrane surface resulting in a build-up of the cake layer. An increase in particle concentration typically leads to an increase in fouling, while smaller particles either causes more, or less, fouling as compared to larger particles [8,9]. In addition, the ionic strength of the solution is an additional factor that can affect membrane fouling. As the ionic strength increases, the fouling potential increases as a result of the double layer compression formed around the colloids [10-12]. With the application of atomic force microscopy (AFM), membrane active-layer characteristic such as surface morphology, pore sizes, and surface porosity can be determined and correlated to membrane fouling behavior. The AFM images presented in the work of Vrijerhoek et al. depict membrane surfaces as having an elevated ridge and depressed valley morphology. They concluded that the fouling behavior was related to the degree of surface roughness [13].

To investigate the effects of chemical and physical interactions between the particles and the membranes, silica dioxide $\left(\mathrm{SiO}_{2}\right)$, titanium dioxide $\left(\mathrm{TiO}_{2}\right)$, and cerium dioxide $\left(\mathrm{CeO}_{2}\right)$ served as foulants during the conduct of the fouling experiments. $\mathrm{SiO}_{2}$ is a stable metal oxide and is generally found in natural waters and has been identified as one of the possible foulants of synthetic membrane processes. A number of studies have been performed using $\mathrm{SiO}_{2}$ in membrane colloidal fouling experiments [5,7,9-13]. $\mathrm{TiO}_{2}$ is a well known photocatalyst, and exhibits properties of oxidative decomposition; the photo-induced ultrahydrophilicity of $\mathrm{TiO}_{2}$ has attracted much interest in both basic and applied sciences. $\mathrm{TiO}_{2}$ has a unique self-cleaning effect in that photocatalysis and hydrophilicity can take place simultaneously on the same surface even though the mechanisms are completely different [14]. By comparison, less research has been conducted on the study of $\mathrm{CeO}_{2}$ in membrane fouling studies. Cerium dioxide has been demonstrated as a self-cleaning catalyst with a strong absorption for ultraviolet radiation but having a lower photocatalytic activity for visible light. In general nanoparticles have been used to modify membrane surface properties in order to enhance membrane performance and mitigate membrane fouling $[15,16]$. The use of nanoparticles in membrane manufacturing allows for both a high degree of fouling control and the ability to produce a desirable membrane structure. Some researchers have tried to synthesize membranes with titanium oxide $\left(\mathrm{TiO}_{2}\right)$ nanoparticles either trapped inside or deposited on the surface to modify the membrane surface 
roughness and hydrophobicity [15,17]. In this study, silica, titanium and cerium nanoparticles were applied to RO and NF membranes in a cross flow flat sheet test unit. The flux decline for RO and NF membranes was then monitored so that comparisons between the different nanoparticles could be accomplished.

The conventional filtration theory for flow through porous media is known as Darcy's law [18]. Considering resistance in series, a fouling model was established by applying a resistance value to each component of membrane fouling. Note that each component contributes to hydraulic resistance and that they act independently from one another. Typical forms of the resistance-in-series model is shown in Equation (1). The pore constriction resistance coefficient $\kappa_{p}$ can be negligible for small pore membranes such as NF and RO.

$$
J=\frac{\Delta p}{\mu\left(\kappa_{m}+\kappa_{c}+\kappa_{p}\right)}
$$

where:

$\kappa_{m}, \kappa_{c}, \kappa_{p}=$ Resistance coefficient for membrane, cake layer, and pore constriction;

$\mu=$ Dynamic viscosity.

This fundamental fouling model has been modified by Hoek [19] by considering the effect of enhanced osmotic pressure. According to this modified model, the osmotic pressure at the RO membrane active layer tends to be enhanced when a cake layer has been formed, depending on cake thickness and concentrate fluid salinity. This phenomenon can be accounted for by incorporating the osmotic pressure difference $\Delta \pi_{m}^{*}$ in the basic filtration model, as follows:

$$
J=\frac{\Delta p-\Delta \pi_{m}^{*}}{\mu\left(\kappa_{m}+\kappa_{c}\right)}
$$

With a constant trans-membrane pressure (TMP), several filtration models have been developed to describe the fouling processes [20]. These models relates the permeate flow $(Q)$, permeate volume $(V)$, the time $(t)$ with the filtration constants for each model $\left(K_{b}, K_{i}, K_{s}, K_{c}\right)$, and the initial permeate flow $\left(Q_{0}\right)$. The mathematical expressions of these models and their assumptions are shown in Table 1 [20]. Among these models, the intermediate blocking filtration and the cake filtration models are applicable for RO and NF membranes. The remaining models are applicable to UF and MF membranes.

Table 1. Constant pressure filtration model.

\begin{tabular}{cll}
\hline Model & \multicolumn{1}{c}{ Equation } & \multicolumn{1}{c}{ Assumption } \\
\hline Complete blocking filtration & $Q=Q_{0}-K_{b} V$ & $\begin{array}{l}\text { Particles are not superimposed on one } \\
\text { another, the blocked surface area is } \\
\text { proportional to the permeate volume }\end{array}$ \\
\hline Intermediate blocking filtration & $\frac{1}{Q}=K_{i} t+\frac{1}{Q_{0}}$ & $\begin{array}{l}\text { Particles can overlap each other, not every } \\
\text { deposited particle block the pores }\end{array}$ \\
\hline Standard blocking filtration & $Q^{1 / 2}=Q_{0}^{1 / 2}-\left(\frac{K_{S} V Q_{O}^{1 / 2}}{2}\right)$ & $\begin{array}{l}\text { Particles are small enough to enter the pores, } \\
\text { the decrease of pore volume is proportional } \\
\text { to the permeate volume }\end{array}$ \\
\hline Cake filtration & $\frac{1}{Q}=\frac{1}{Q_{0}}+K_{c} V$ & $\begin{array}{l}\text { Particles are big enough to not enter the } \\
\text { pores, and therefore forms a cake layer on } \\
\text { the surface }\end{array}$ \\
\hline
\end{tabular}


The applications of these models can be seen in many publications. Mohammadi and his coworkers studied the flux decline in RO processes during separation of oil-water emulsions, where it was observed that the best fitting was the intermediate blocking filtration model [20]. Lim investigated the fouling behavior of microfiltration membranes in activated sludge system [21]. The results show that the main types of membrane fouling in this case were attributed to initial pore blocking (standard blocking filtration model) followed by cake formation (cake filtration model). Bolton compared these four models in application to MF and UF of biological fluids, where the combination of a cake filtration model with a complete pore blocking model resulted in the best fit of experimental data [22]. Alternatively, in a cross flow UF experiment conducted by Tarabara [8], cake formation was investigated under variable particle size and solution ionic strength. It was found that a dense layer of the colloidal deposit formed adjacent to the membrane with an abrupt transition to a much more porous layer near the membrane-suspension interface [8]. These studies from MF and UF implied that different models should be considered at different phases when simulating fouling behavior of RO and NF. Other effort has been explored to investigate the effects of pressure, membrane rejection, fluid shear, and the effect of cake-enhanced concentration polarization on the fouling behavior of different membranes. It was concluded pressure, rejection and fluid shear are important in determining the cake deposition under most testing conditions [23].

The objective of this study is to investigate the productivity of RO and NF membranes under laboratory-scale conditions. It is postulated that nanoparticles impact flux decline depending on membrane morphology. This paper reports on the results of an investigation conducted to investigate the intrinsic mechanism of nanoparticle interaction with surface properties on the productivity of membranes in aqueous environments.

\section{Experimental Design}

\subsection{Preparation of Membrane and Nanoparticles}

It has been found that surface chemical heterogeneities can provide favorable sites for attachment onto what is otherwise an unfavorable surface for colloid adherence [24]. To take into account different membrane surface properties, both RO and NF membrane sheets having different surface roughness were purchased for study (Sterlitech, Kent, WA, USA). The specifications of the membranes investigated in this study are shown in Table 2. The membrane samples were acquired as dry sheets and were stored in distilled (DI) water at room temperature prior to assembly into flat-sheet test cells. The membranes were characterized for intrinsic physical and chemical properties through the use of surface roughness and contact angle.

Table 2. Specification of membranes used in the experiments.

\begin{tabular}{cccccc}
\hline Designation & Membrane type & Manufacturer & Polymer & $*$ MWCO & Pressure, psi \\
\hline BW30 & RO & Dow & Polyamide & $100 \mathrm{D}$ & 260 \\
XLE & RO & Dow & Polyamide & $100 \mathrm{D}$ & 130 \\
CK & NF & GE Osmonics & Cellulose Acetate & 2000 & 220 \\
\hline
\end{tabular}

* MWCO: Molecular Weight Cut Off. 
Commercial $\mathrm{TiO}_{2}$ (anatase, 99\%, $15 \mathrm{~nm}$ ), $\mathrm{CeO}_{2}(99.9 \%, 50-105 \mathrm{~nm})$, and $\mathrm{SiO}_{2}(99+\%, 80 \mathrm{~nm})$ nanoparticles (NanoAmor, Houston, TX, USA) were used in the fouling experiments. The nanoparticles were supplied in powder forms. The true densities were $2.2-2.9 \mathrm{~g} / \mathrm{cm}^{3}$ for $\mathrm{SiO}_{2}$, $3.9 \mathrm{~g} / \mathrm{cm}^{3}$ for $\mathrm{TiO}_{2}$, and $7.1 \mathrm{~g} / \mathrm{cm}^{3}$ for $\mathrm{CeO}_{2}$. This size range is to ensure the particles can pass through a typical cartridge filter. Currently, the engineering design standard of care in pretreatment of brackish water RO desalination and groundwater NF pre-treatment is the use of cartridge filters that typically possess $5 \mu \mathrm{m}$ nominal pore size. The nanoparticles used in this work are on the order of $0.2 \mu \mathrm{m}$ or less and would pass through a standard cartridge filter. Nanoparticle concentrations were determined after several trials until a flux decline was observed. Prior to each experiment, the nanoparticles were dissolved in DI water and the resultant suspension was sonicated in a water bath ultrasonicator for 30 min to maintain suspension.

\subsection{Membrane Performance Testing}

Membrane productivity tests were performed using a CF042 cross flow flat sheet membrane filtration unit (CF042, Sterlitech, Kent, WA, USA). The membrane cell allows for evaluation of membrane film with an active surface area of $42 \mathrm{~cm}^{2}$. The cell dimension is $9.207 \mathrm{~cm} \times 4.572 \mathrm{~cm} \times 30 \mathrm{~mL}$. The pre-cut membrane was loaded into the cell and the system was run under recommended pressure for 20 min with DI water to remove any residual chemicals from manufacturing. The water was then drained and the system was filled with testing solution. The schematic flow diagram for the flat sheet testing instrument is shown in Figure 1. A 1.5 gal reservoir provided feed water into a high pressure pump. The flow rate and pressure were adjusted by the two valves located on the bypass and concentrate flow tubes. The feed flow was maintained at $757 \mathrm{~mL} / \mathrm{min}$, providing a cross flow velocity of $0.18 \mathrm{~m} / \mathrm{s}$ (Reynolds number is 307). The permeate and concentrate flows were recycled into the feed tank to ensure a constant background electrolyte condition. The temperature was maintained at $21{ }^{\circ} \mathrm{C}$ with a coil immersed in the feed tank and connected to a chiller unit. After a constant flux was achieved, an appropriate volume of premixed $\mathrm{NaCl}$ solution was added to provide a $0.05 \mathrm{M}$ salt concentration. After the $\mathrm{NaCl}$ solution was added, the unit was allowed to equilibrate for $20 \mathrm{~h}$ to allow compaction of the new membranes. A dose of the resultant nanoparticle suspension was then added into the feed tank to provide a feed concentration of either $135 \mathrm{mg} / \mathrm{L}$ or $405 \mathrm{mg} / \mathrm{L}$. The flux was monitored by a flow meter continuously for the duration of experiment and recorded on a laboratory computer.

For water qualities, $\mathrm{pH}$, conductivity and the turbidity were measured at the beginning, the end, and several points during the experiments to maintain constant physical and chemical conditions throughout the test. Three runs were conducted for each membrane: baseline, $135 \mathrm{mg} / \mathrm{L}$ nanoparticle addition, and $405 \mathrm{mg} / \mathrm{L}$ nanoparticle addition. Each individual run lasted approximately twenty hours. The membrane productivities tested with different nanoparticles were studied in terms of flux decline and salt rejection over time. Relationships between surface properties and membrane productivity were quantitatively evaluated in this investigation. 
Figure 1. Flat sheet unit testing flow diagram.

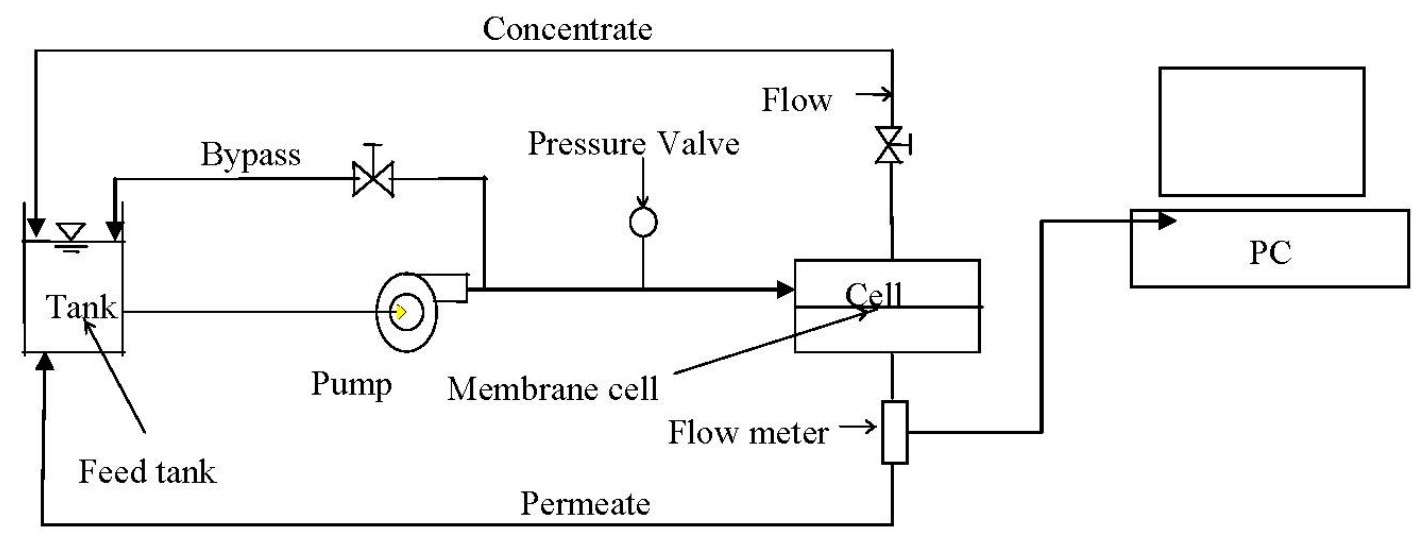

\subsection{Membrane Surface Properties}

Membrane hydrophobicity and surface roughness were determined and evaluated in this study. Membrane hydrophobicity was determined by measuring the contact angle between the membrane surface and a water droplet. Contact angle measurements were obtained through the captive bubble technique. A goniometer manufactured by Rame-Hart was used to measure the contact angle.

The surface roughness of four different membranes was measured by a Digital Instruments Nanoscope Atomic Force Microscope. The AFM scans the surface with a cantilevered tip, generating a three-dimensional elevation map. The tip was operated in "tapping" mode to reduce the sample damage and maximize resolution. Surface elevation data can be used to determine the average roughness and the root mean squared (RMS) roughness. The average roughness is simply the average deviation of the peaks and valleys from the center plane; the RMS roughness is defined as the standard deviation of the peaks and valleys from the center plane. Both these parameters were used to determine the correlations between the fouling data and the membrane surface morphology.

\section{Results}

This section discussed the effect of chemical and physical characteristics of the membranes and nanoparticles on membrane performance. Theoretical analysis of the results was elaborated to understand the mechanisms of interaction between these nanoparticles and membrane productivity. The effect of nanoparticle concentration on the productivity of RO and NF membranes at a constant feed ionic strength are shown in the following figures. Results are presented in terms of relative flux as function of time. Relative flux is expressed as the flux at any time during the test divided by the initial flux $\left(\mathrm{f} / \mathrm{f}_{0}\right)$. The baseline represents the runs with the background solution $(0.05 \mathrm{M} \mathrm{NaCl})$ and without nanoparticles. The difference between the permeate flux with nanoparticles in the feed stream and the baseline indicates the net contribution of nanoparticles to membrane productivity.

\subsection{Effect of $\mathrm{SiO}_{2}$ on Flux Decline}

Figures 2-4 show the effect of $\mathrm{SiO}_{2}$ concentration on the flux decline rate of $\mathrm{RO}$ and $\mathrm{NF}$ membranes at a constant ionic strength in the feed solution. The results from the BW30 and XLE membranes show that greater flux decline is obtained at a higher $\mathrm{SiO}_{2}$ particle dosage, while no 
obvious flux decline was observed for the CK membranes. With an increasing particle concentration, the rate of mass transport of particles toward the membrane surface increases, thereby, the overall rate of particle deposition onto the membrane surface increases. As a result, the total mass of deposited particles increases, which resulting in higher resistance to water permeating the membrane and thus reduced water flux. Figure 5 compares the rate of flux decline with a given concentration. The BW30 and XLE membranes have a higher relative flux decline rate, while the flux through the CK membrane decreases at a much lower rate relative to the other three. This behavior can be attributed to the pore sizes and to the difference in the surface roughness of these four membranes. RO membranes are almost nonporous while the nominal pore dimension for NF membranes is about $0.001 \mu \mathrm{m}$ [18]. It is also noted that initial flux, shown in Table 3, also plays a role in determining the flux decline rate. Typically a higher initial flux results in a higher flux decline rate [7]. The initial flux for the BW30 membrane is slightly higher than the XLE membrane, but the flux decline rate is similar for these two membranes due to the differences in their surface morphology. The analysis of membrane surface roughness is discussed later in this study.

Figure 2. Relative flux as a function of time with $\mathrm{SiO}_{2}$ at three different particle concentrations for the BW30 membranes.

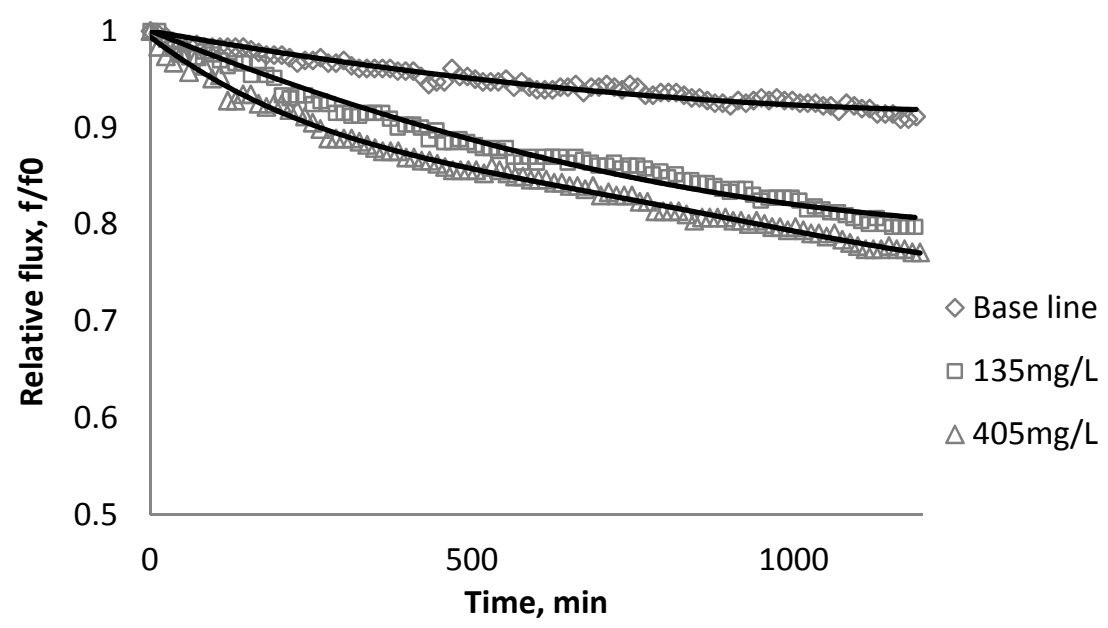

Figure 3. Relative flux as a function of time with $\mathrm{SiO}_{2}$ at three different particle concentrations for the XLE membranes.

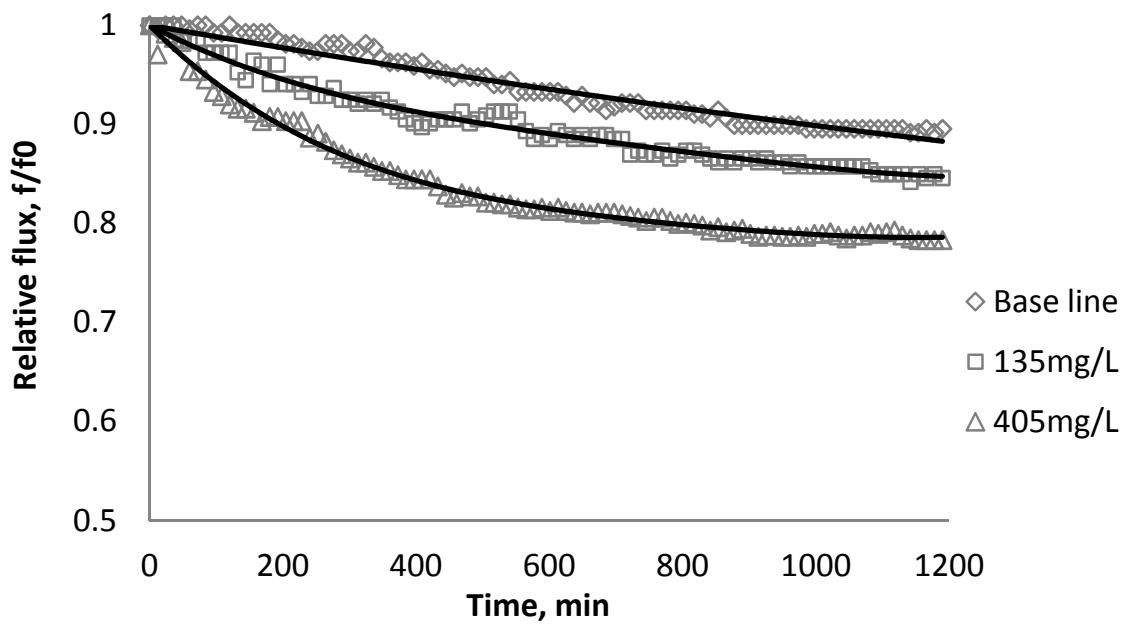


Figure 4. Relative flux as a function of time with $\mathrm{SiO}_{2}$ at three different particle concentrations for the $\mathrm{CK}$ membranes.

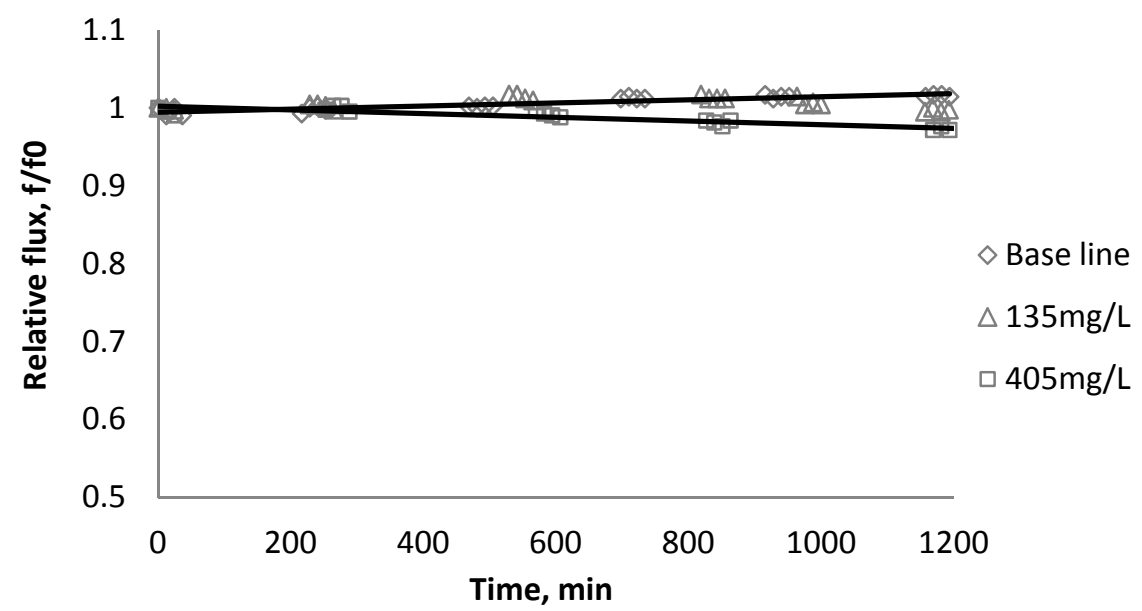

Figure 5. Relative flux as a function of time with: (a) $135 \mathrm{mg} / \mathrm{L}$; (b) $405 \mathrm{mg} / \mathrm{L}$ as $\mathrm{SiO}_{2}$ in the feed stream to three different membranes.

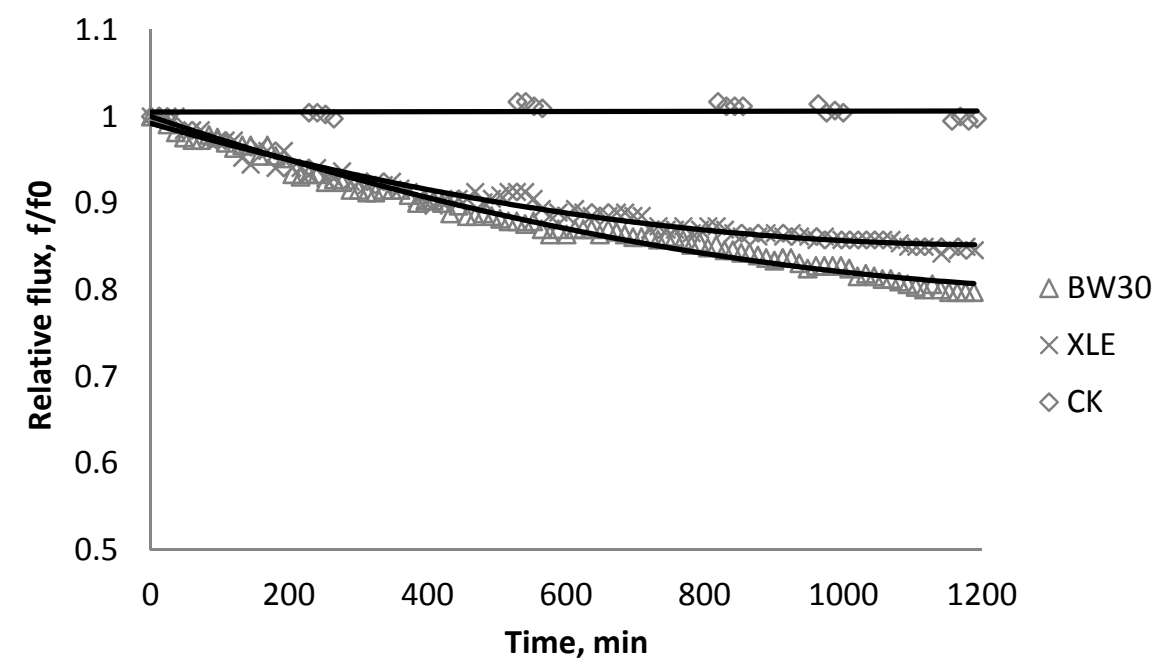

(a)

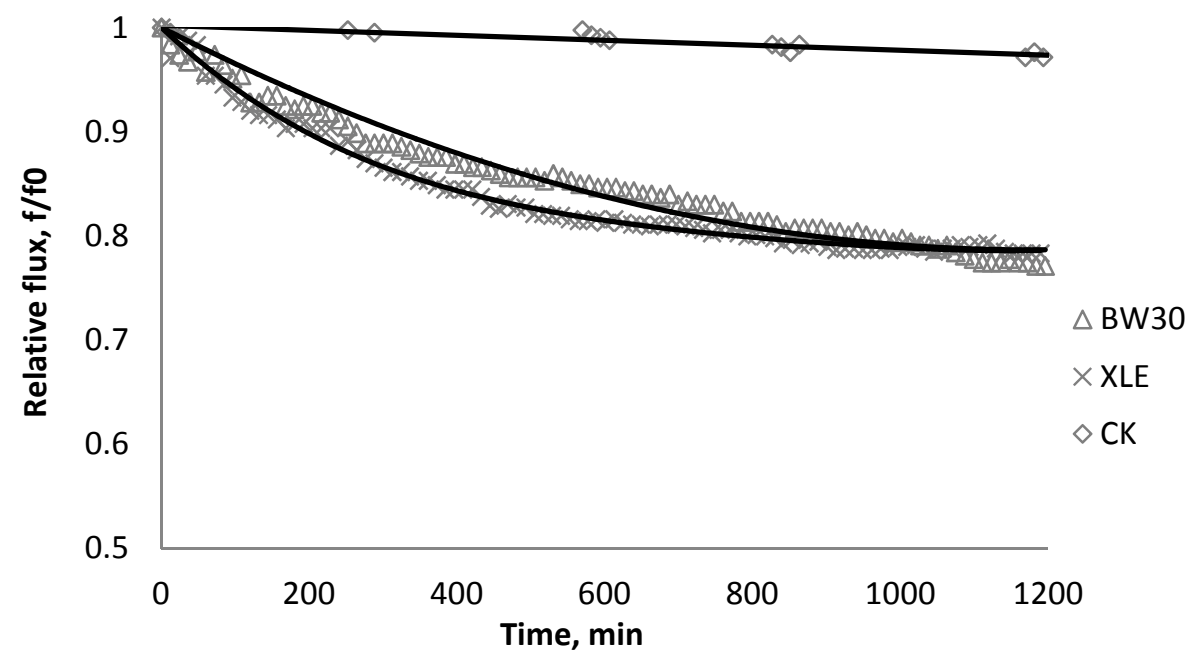

(b) 
Table 3. Initial flux for membranes being tested using $\mathrm{SiO}_{2}$.

\begin{tabular}{cccc}
\hline Initial flux & BW30 & XLE & CK \\
\hline $\mathrm{m} / \mathrm{s}$ & $1.31 \times 10^{-5}$ & $1.00 \times 10^{-5}$ & $6.54 \times 10^{-6}$ \\
$\mathrm{gal} / \mathrm{sfd}$ & 27.78 & 21.20 & 13.87 \\
\hline
\end{tabular}

\subsection{Effect of $\mathrm{TiO}_{2}$ on Flux Decline}

The productivity of the RO and NF membranes with $\mathrm{TiO}_{2}$ is presented in Figures 6-8. Comparisons of the effect of $\mathrm{TiO}_{2}$ on flux decline rate with a given concentration are shown in Figure 9. The experiments were conducted with $0.05 \mathrm{M} \mathrm{NaCl}$ serving as a background solution. The feed flow was maintained at $757 \mathrm{~mL} / \mathrm{min}$. The initial flux is shown in Table 4.

Figure 6. Relative flux as a function of time with $\mathrm{TiO}_{2}$ at three different particle concentrations for the BW30 membranes.

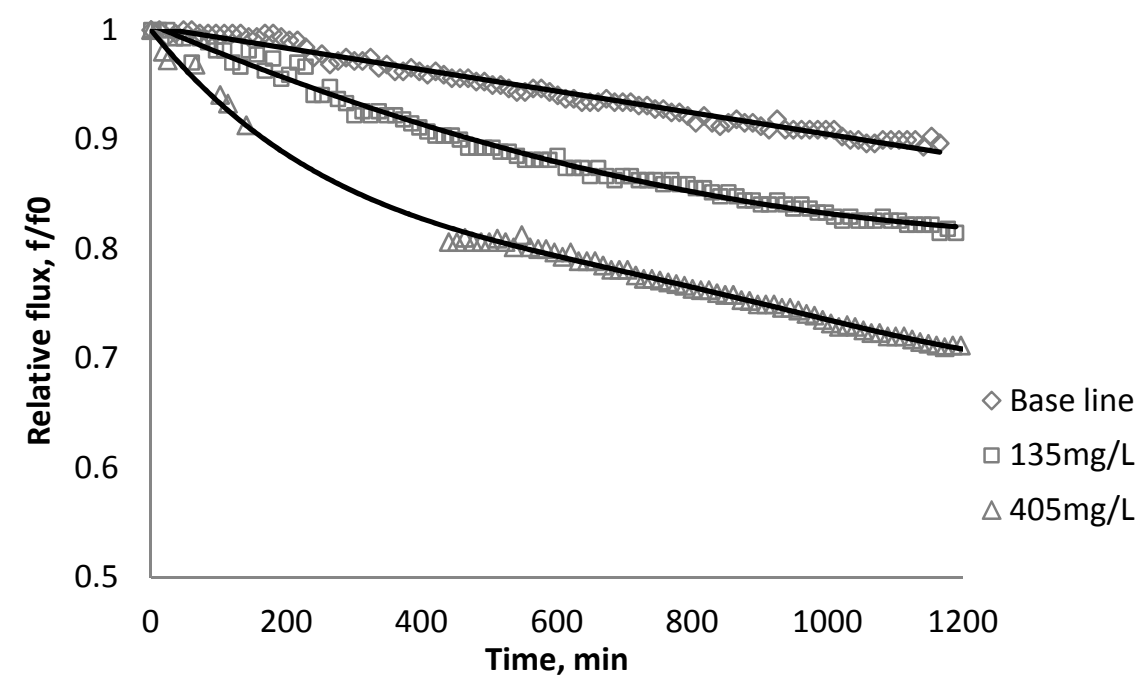

Figure 7. Relative flux as a function of time with $\mathrm{TiO}_{2}$ at three different particle concentrations for the XLE membranes.

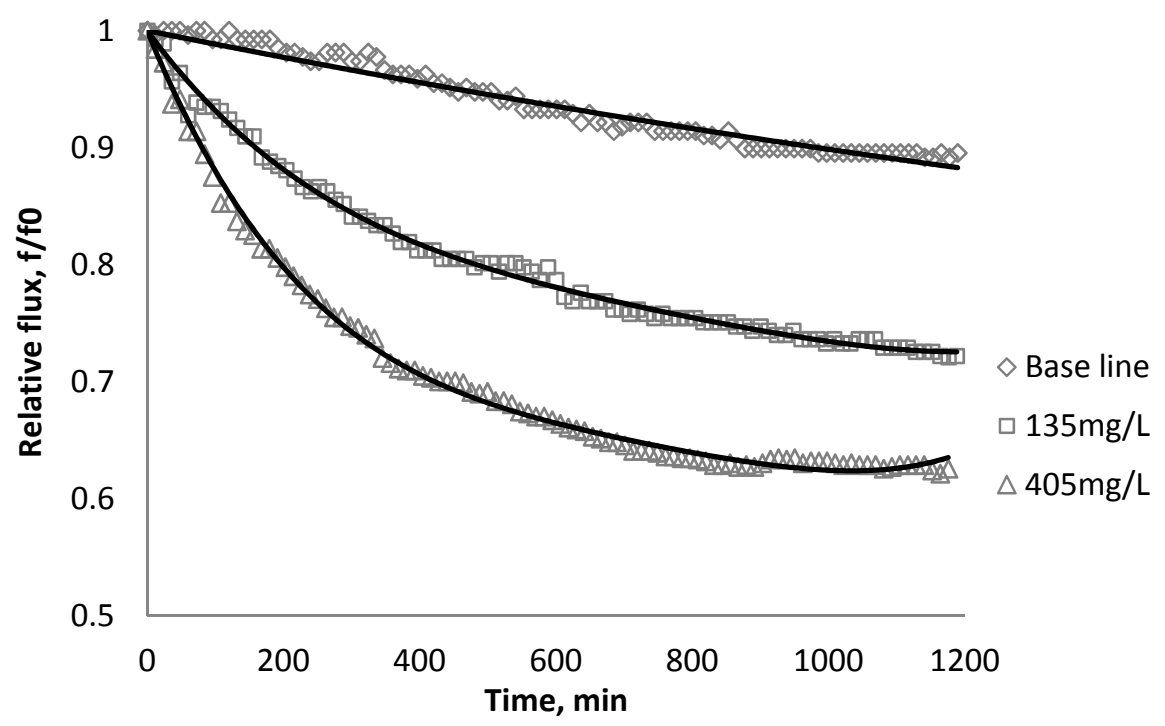


Results from Figures 6 and 7 indicate there is significant flux decline for the BW30 and XLE membranes, while Figure 9 shows no obvious flux decline for the CK membranes. When compared on the basis of percent flux decline at the end of each run, the membranes rank in the following order: $C K<B W 30<X L E$. It is noted that compared with $\mathrm{SiO}_{2}, \mathrm{TiO}_{2}$ aggravates fouling for the $\mathrm{BW} 30$ and XLE membranes but does not affect the fouling rate for the $\mathrm{CK}$ membranes. One possible explanation is that the average size of $\mathrm{TiO}_{2}(15 \mathrm{~nm})$ is smaller than $\mathrm{SiO}_{2}(80 \mathrm{~nm})$ and the density of $\mathrm{TiO}_{2}$ $\left(3.9 \mathrm{~g} / \mathrm{cm}^{3}\right)$ is higher than $\mathrm{SiO}_{2}\left(2.2 \mathrm{~g} / \mathrm{cm}^{3}\right)$, thus the cake layer formed from deposited $\mathrm{TiO}_{2}$ is less porous than that from $\mathrm{SiO}_{2}$, and thus produces higher resistance to water permeating the membranes.

Figure 8. Relative flux as a function of time with $\mathrm{TiO}_{2}$ at three different particle concentrations for the $\mathrm{CK}$ membranes.

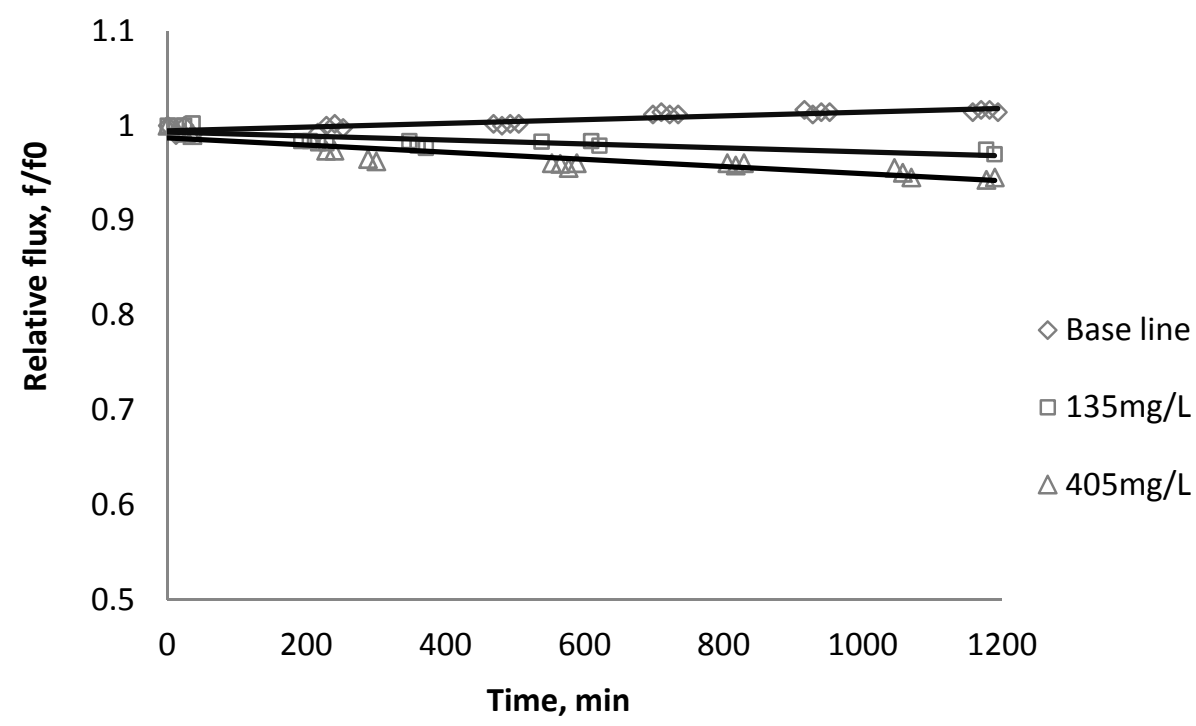

Figure 9. Relative flux as a function of time with: (a) $135 \mathrm{mg} / \mathrm{L}$; (b) $405 \mathrm{mg} / \mathrm{L}$ as $\mathrm{TiO}_{2}$ in the feed stream to three different membranes.

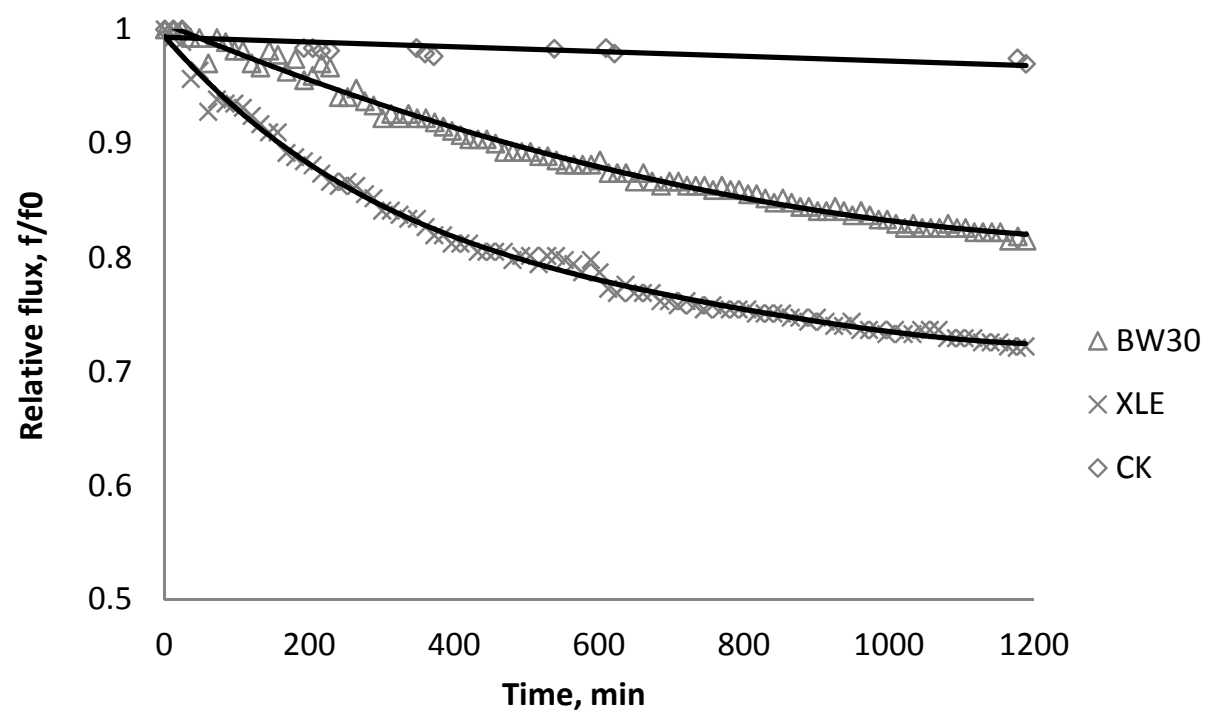

(a) 
Figure 9. Cont.

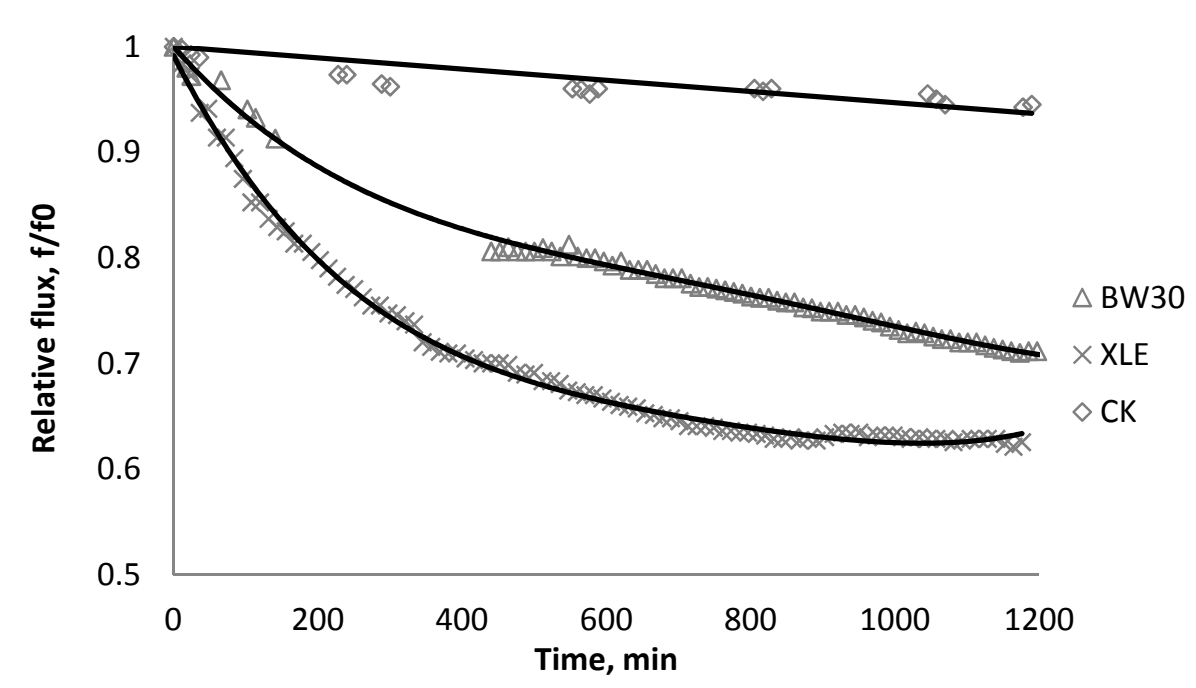

(b)

Table 4. Initial flux for membranes being tested using $\mathrm{TiO}_{2}$.

\begin{tabular}{cccc}
\hline Initial flux & BW30 & XLE & CK \\
\hline $\mathrm{m} / \mathrm{s}$ & $1.07 \times 10^{-5}$ & $1.10 \times 10^{-5}$ & $6.59 \times 10^{-6}$ \\
$\mathrm{gal} / \mathrm{sfd}$ & 22.69 & 23.33 & 13.98 \\
\hline
\end{tabular}

\subsection{Effect of $\mathrm{CeO}_{2}$ on Flux Decline}

Figures 10-12 show the effect of $\mathrm{CeO}_{2}$ on the productivity of BW30, XLE, and CA membranes at a constant ionic strength in the feed solution. Comparisons of the effect of $\mathrm{CeO}_{2}$ with a given concentration on flux decline rate are shown in Figure 13.

Figure 10. Relative flux as a function of time with $\mathrm{CeO}_{2}$ at three different particle concentrations for the BW30 membranes.

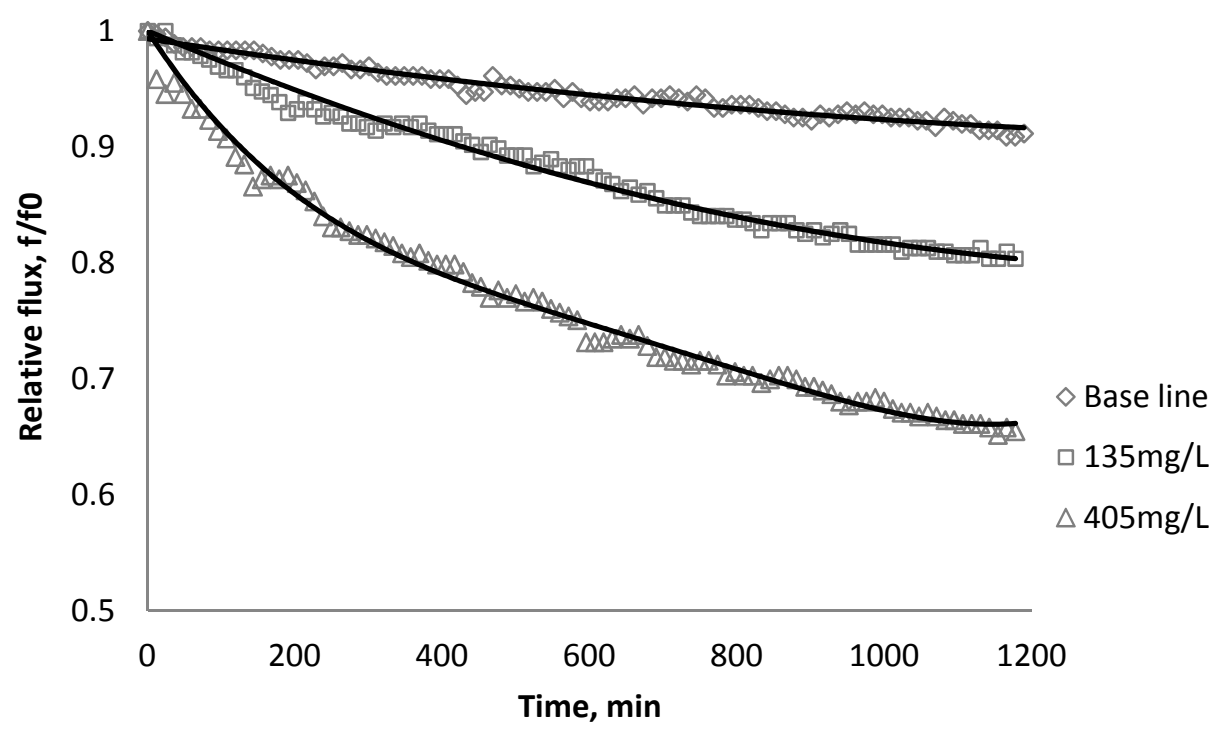


The experiments were conducted with $0.05 \mathrm{M} \mathrm{NaCl}$ serving as a background solution. The feed flow was maintained at $757 \mathrm{~mL} / \mathrm{min}$. The initial flux is shown in Table 5. Similar to $\mathrm{SiO}_{2}$ and $\mathrm{TiO}_{2}$, there is significant flux decline for BW30 and XLE membranes when dosing with $\mathrm{CeO}_{2}$, while no obvious flux decline was observed for CK membranes. The magnitude of flux decline follows the same trend as testing with $\mathrm{TiO}_{2}$ : the XLE membrane shows the most severe flux decline over the testing period, followed by the BW30 membrane; the CK membranes exhibit the least flux decline which indicates fouling resistant properties.

Figure 11. Relative flux as a function of time with $\mathrm{CeO}_{2}$ at three different particle concentrations for the XLE membranes.

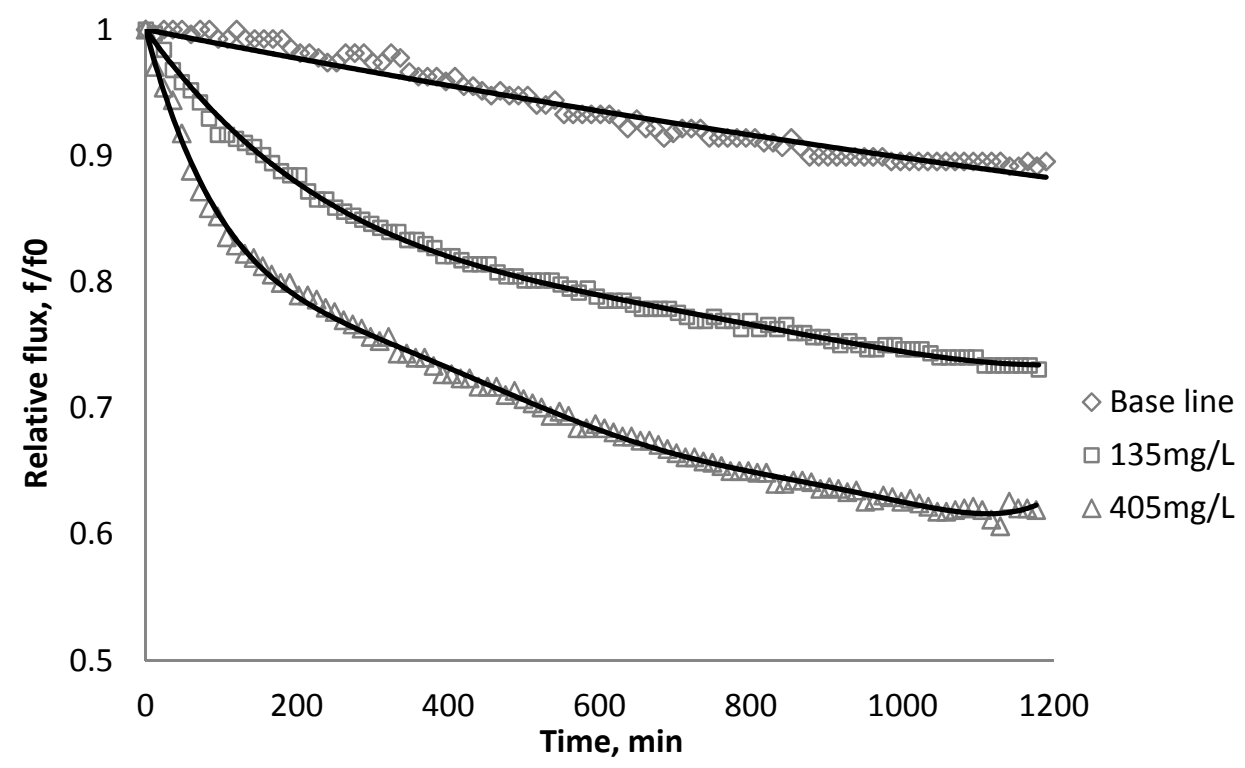

Figure 12. Relative flux as a function of time with $\mathrm{CeO}_{2}$ at three different particle concentrations for the $\mathrm{CK}$ membranes.

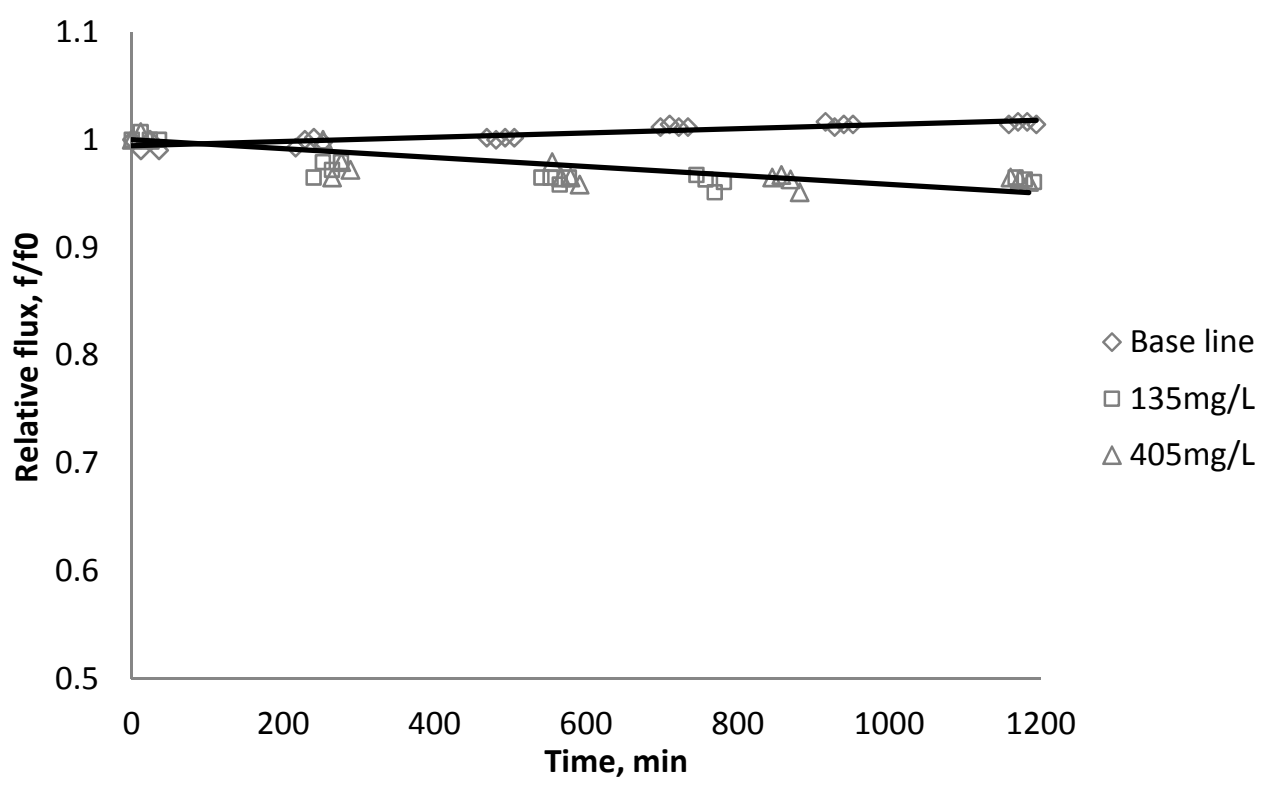


Figure 13. Relative flux as a function of time with: (a) $135 \mathrm{mg} / \mathrm{L}$; (b) $405 \mathrm{mg} / \mathrm{L}$ as $\mathrm{CeO}_{2}$ in the feed stream to three different membranes.

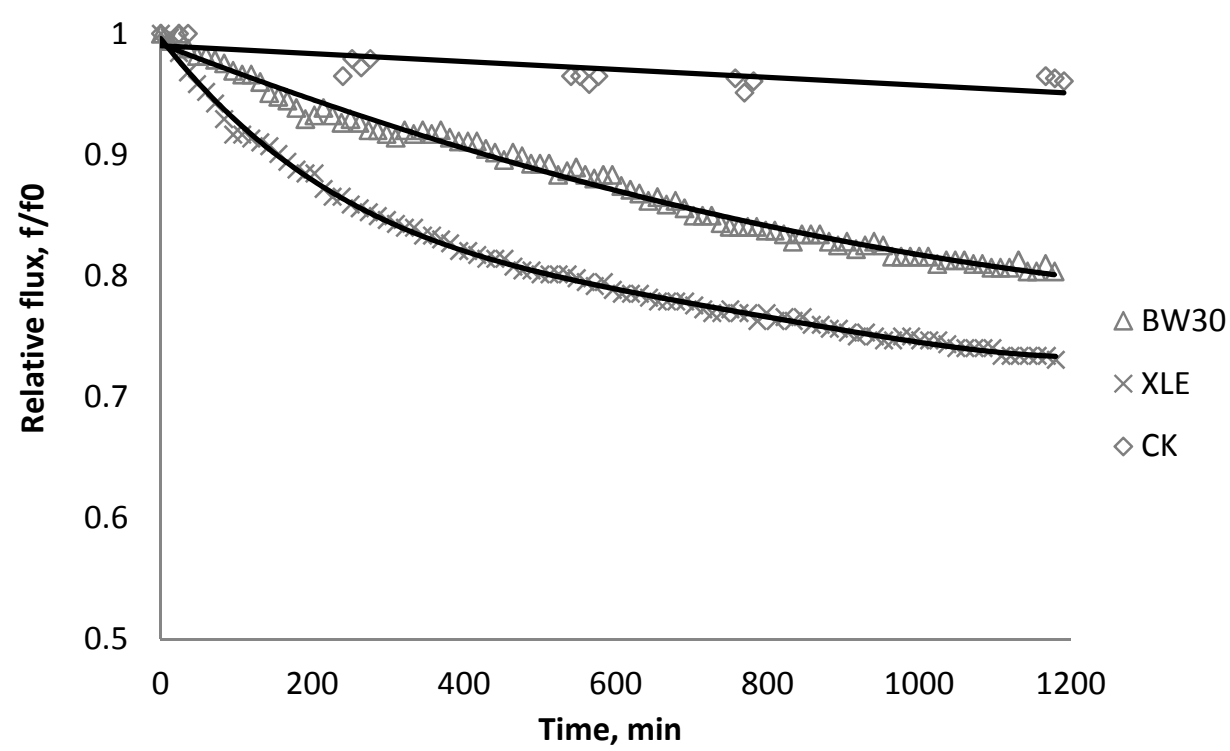

(a)

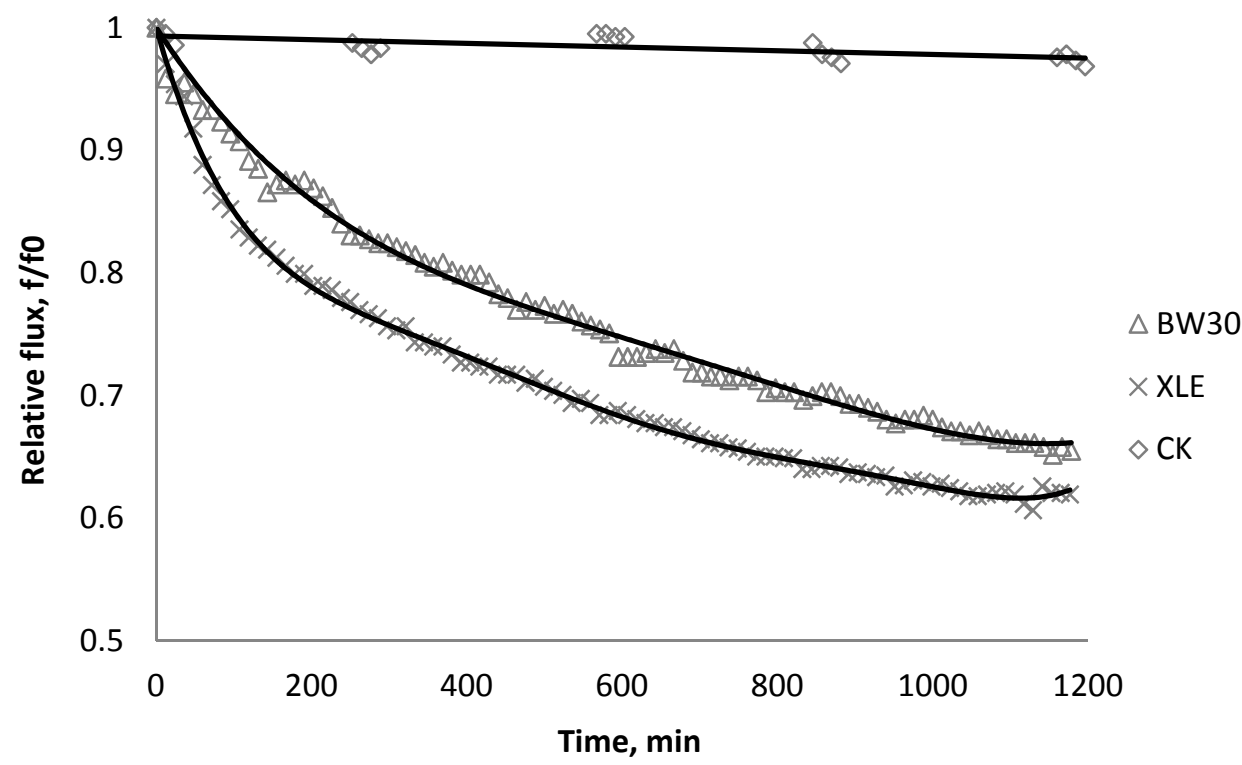

(b)

Table 5. Initial flux for membranes being tested using $\mathrm{CeO}_{2}$.

\begin{tabular}{cccc}
\hline Initial flux & BW30 & XLE & CK \\
\hline $\mathrm{m} / \mathrm{s}$ & $1.29 \times 10^{-5}$ & $1.24 \times 10^{-5}$ & $6.68 \times 10^{-6}$ \\
$\mathrm{gal} / \mathrm{sfd}$ & 27.35 & 26.29 & 14.16 \\
\hline
\end{tabular}

\subsection{Effect of Cross Flow Velocity}

Experiments similar to those in Figure 14 were carried out with a $135 \mathrm{mg} / \mathrm{L} \mathrm{SiO}_{2}$ particle suspension and the BW30 RO membrane to investigate the effect of cross flow velocity on the rate of flux decline. Results in Figure 14 indicate decreasing cross flow velocity from $0.71 \mathrm{~m} / \mathrm{s}$ to $0.24 \mathrm{~m} / \mathrm{s}$ 
(corresponding to Reynolds numbers of 1210 and 410, respectively) at an ionic strength of $0.05 \mathrm{M}$ $\mathrm{NaCl}$ resulted in significant fouling.

Figure 14. Relative flux as a function of time with the BW30 RO membrane at different cross flow velocity. The experiments were conducted with $135 \mathrm{mg} / \mathrm{L} \mathrm{SiO}_{2}$ and $0.05 \mathrm{M}$ $\mathrm{NaCl}$ serving as a background solution.

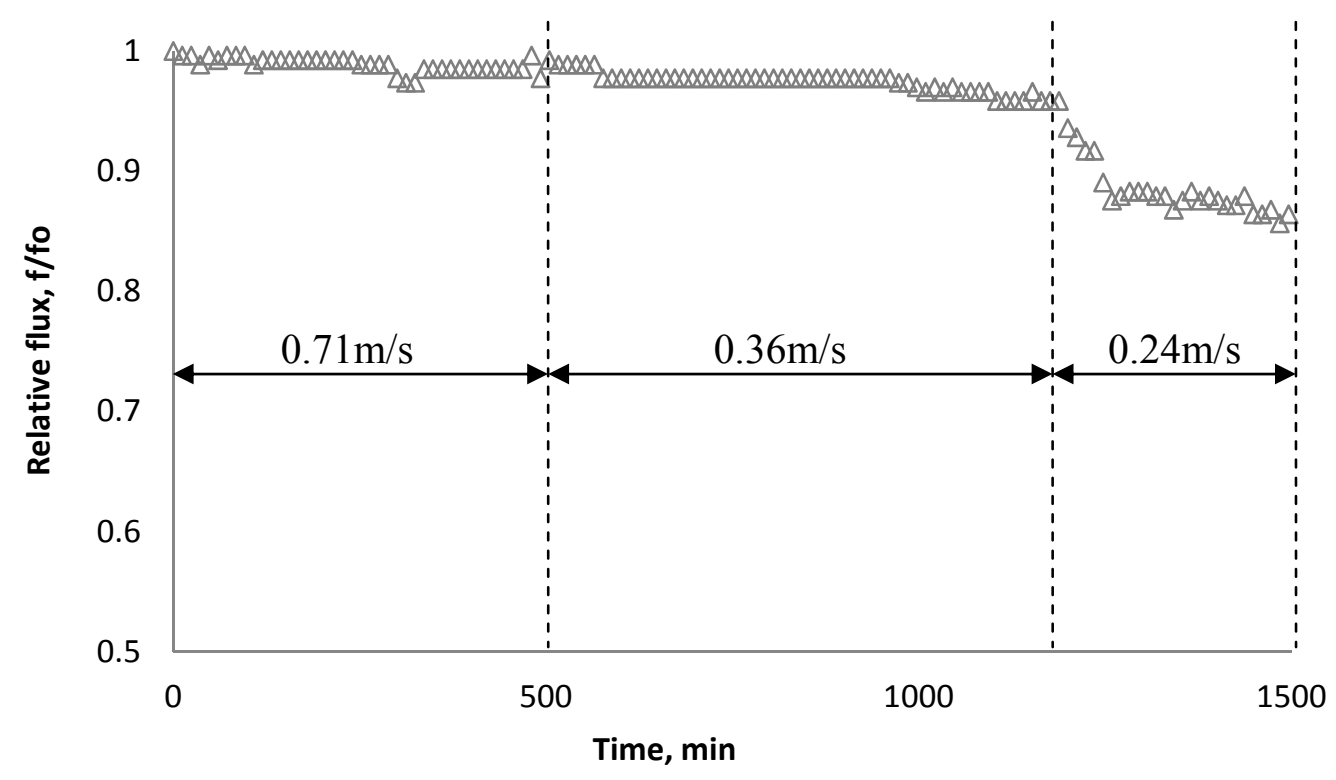

\subsection{Effect of Nanoparticles on Salt Rejection}

Salt rejection was measured at the beginning, the end, and several points during the fouling experiments. The results in Figures 15-17 show that for the BW30 membranes, salt rejection stays stable when tested with $\mathrm{SiO}_{2}$ or $\mathrm{TiO}_{2}$, but declines slightly when tested with $\mathrm{CeO}_{2}$. Similar to the BW30 membranes, the XLE membranes show constant salt rejection over time when tested with $\mathrm{SiO}_{2}$ or $\mathrm{TiO}_{2}$, but the rejection declines faster when the feed is injected with $\mathrm{CeO}_{2}$. For the three particles being tested, the CK membranes show a $10 \%$ decrease in salt rejection over the testing period. The decline in salt rejection can be attributed to the accumulated mass on the membrane surface, which may entrap dissolved salts, thus enhancing their passage through the membrane [19].

\subsection{Fouling Experiment with Desalination Plant Water}

Extended membrane productivity experiments were conducted using RO feed water from a sea water desalination plant located in Tampa Bay, FL, USA. This plant is capable of producing 25 MGD of desalinated water. The tested water was sampled after the cartridge filters but before the RO feed pressure pump. The feed water TOC level in pretreated seawater approximated $4.2 \mathrm{mg} / \mathrm{L}$, the salinity ranged from 43.8 to 44.6 , and the $\mathrm{pH}$ measured approximately $6.8 \mathrm{pH}$ units.

Before the fouling experiment, the raw water was diluted ten to one to reduce the salt concentration such that the feed water conductivity was about $4800 \mu \mathrm{s} / \mathrm{cm}$, which is similar to the laboratory tested condition previously examined. Each particle was dosed into the feed tank with a concentration of $135 \mathrm{mg} / \mathrm{L}$ after $20 \mathrm{~h}$ of particle free solution testing. The fouling behavior of the BW30 membranes 
were investigated and the relative flux with each particle addition using $0.05 \mathrm{M} \mathrm{NaCl}$ solution and diluted Tampa Bay water are shown in Figure 18a,b. Using a $0.05 \mathrm{M} \mathrm{NaCl}$ solution as the basis for the suspensions, the flux decreases at a similar speed. When using RO feed water from the Tampa Bay desalination plant, the permeate flux declines at different rates; feeding with $\mathrm{TiO}_{2}$ results in the highest flux decline, and $\mathrm{CeO}_{2}$ appears to relieve the fouling compared to other two particles. It is noted that the flux decline between the laboratory-grade and diluted seawater feed solutions were found to be different. The scope of the research presented herein did not fully evaluate the constituents present that would explain this difference; however, it is noted that the ionic strength differences may help explain the trends observed. Additional studies are being conducted to further elucidate observed differences.

Figure 15. Relative salt rejection as a function of time with $\mathrm{SiO}_{2}$ : (a) $135 \mathrm{mg} / \mathrm{L}$; (b) $405 \mathrm{mg} / \mathrm{L}$.

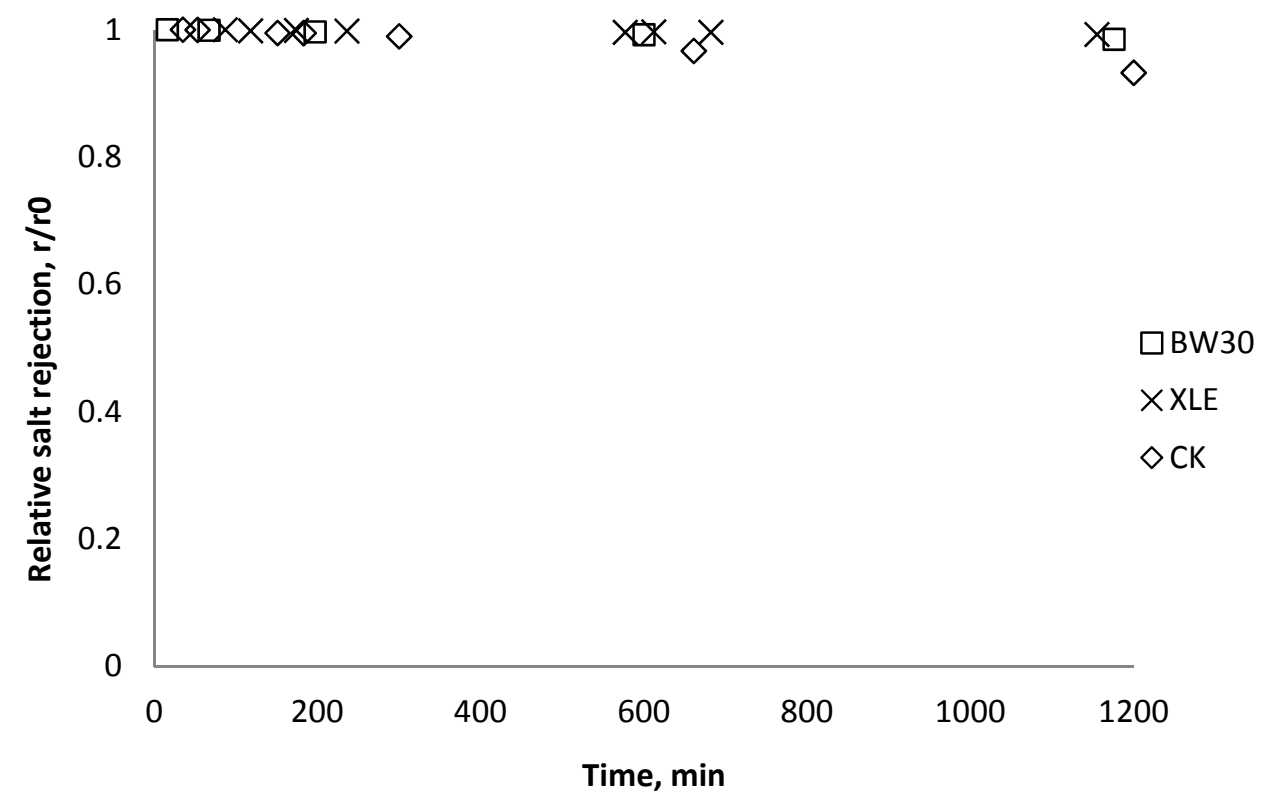

(a)

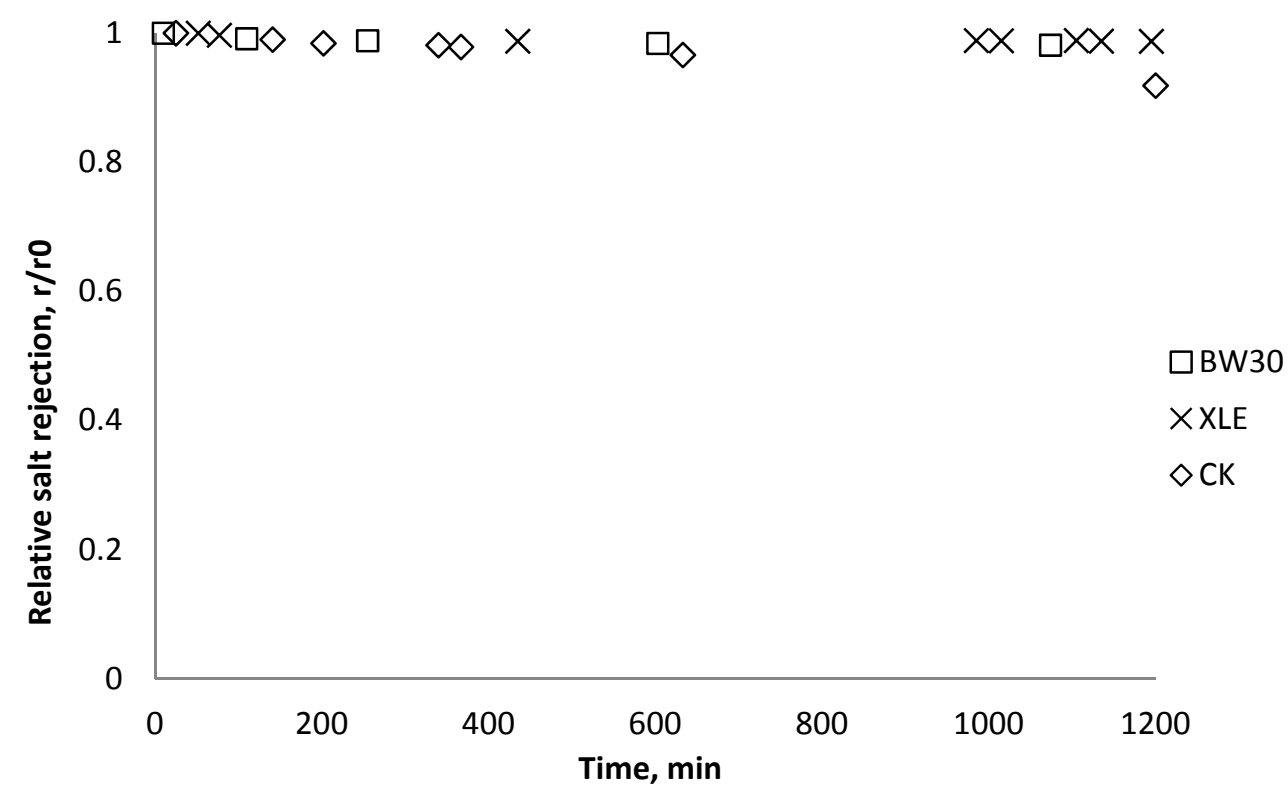

(b) 
Figure 16. Relative salt rejection as a function of time with $\mathrm{TiO}_{2}$ : (a) $135 \mathrm{mg} / \mathrm{L}$; (b) $405 \mathrm{mg} / \mathrm{L}$.

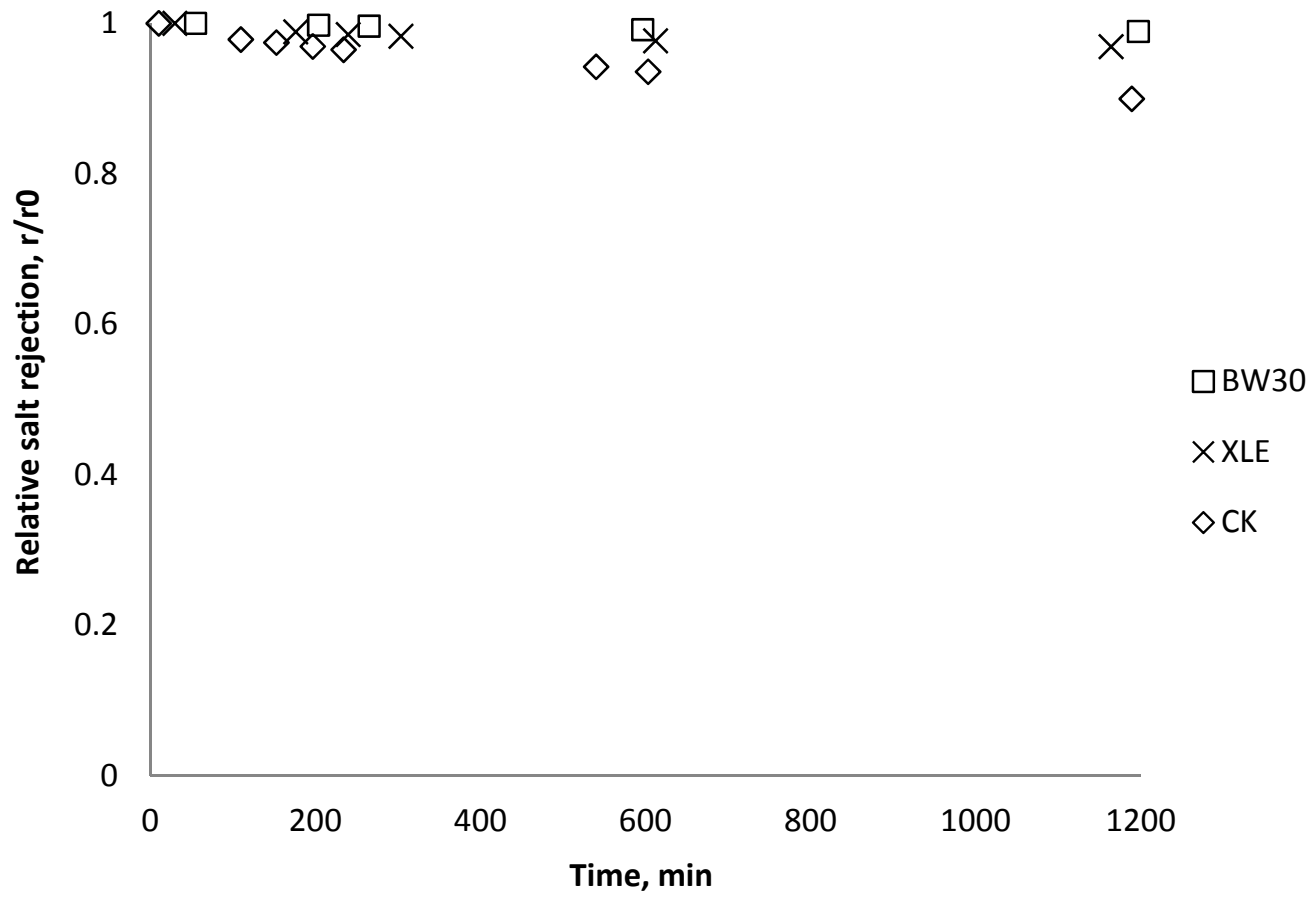

(a)

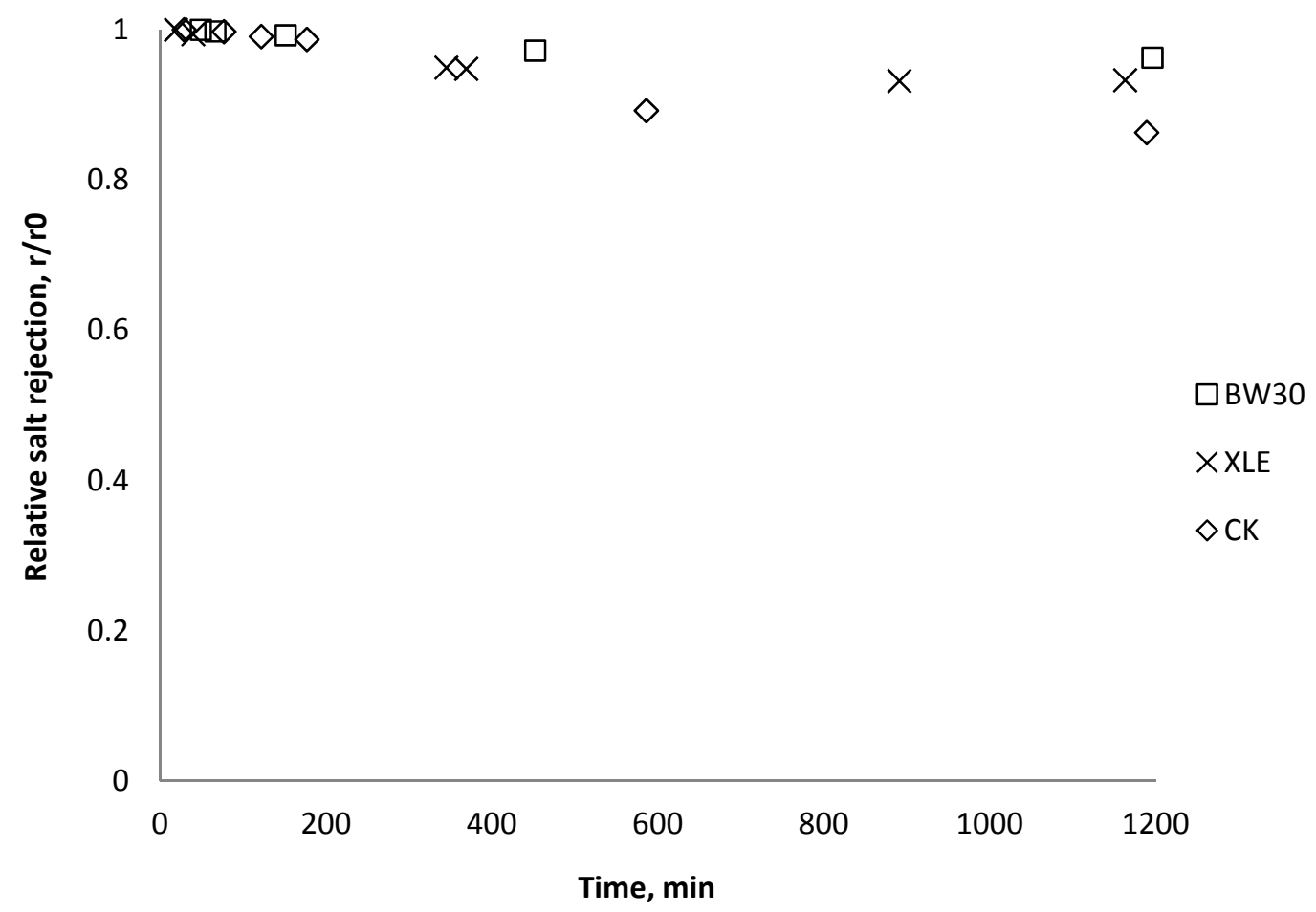

(b) 
Figure 17. Relative salt rejection as a function of time with $\mathrm{CeO}_{2}$ : (a) $135 \mathrm{mg} / \mathrm{L}$; (b) $405 \mathrm{mg} / \mathrm{L}$.

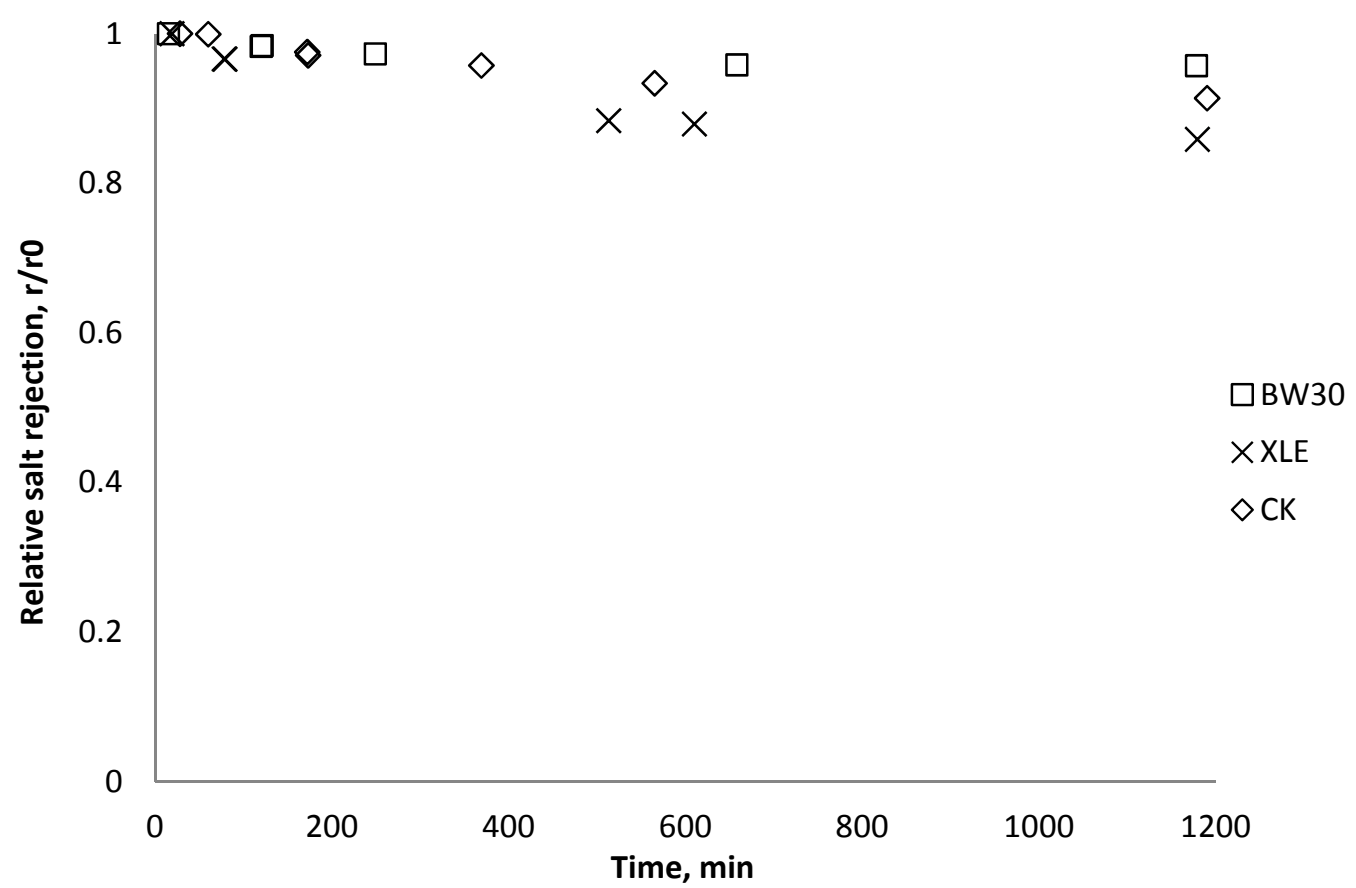

(a)

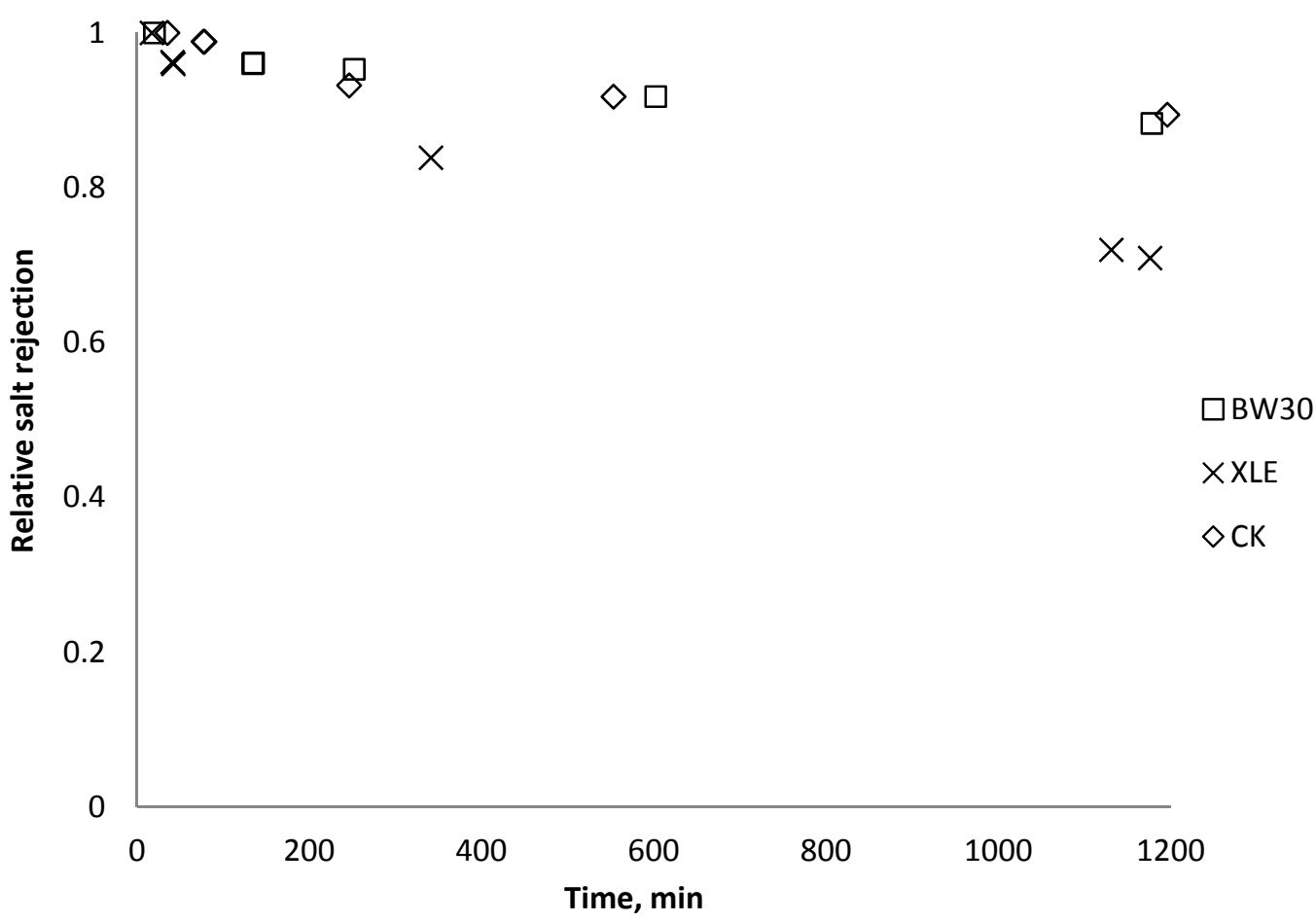

(b) 
Figure 18. Relative flux as a function of time using different source water: (a) $0.05 \mathrm{M}$ $\mathrm{NaCl}$; (b) diluted reverse osmosis (RO) feed water from Tampa Bay desalination plant.

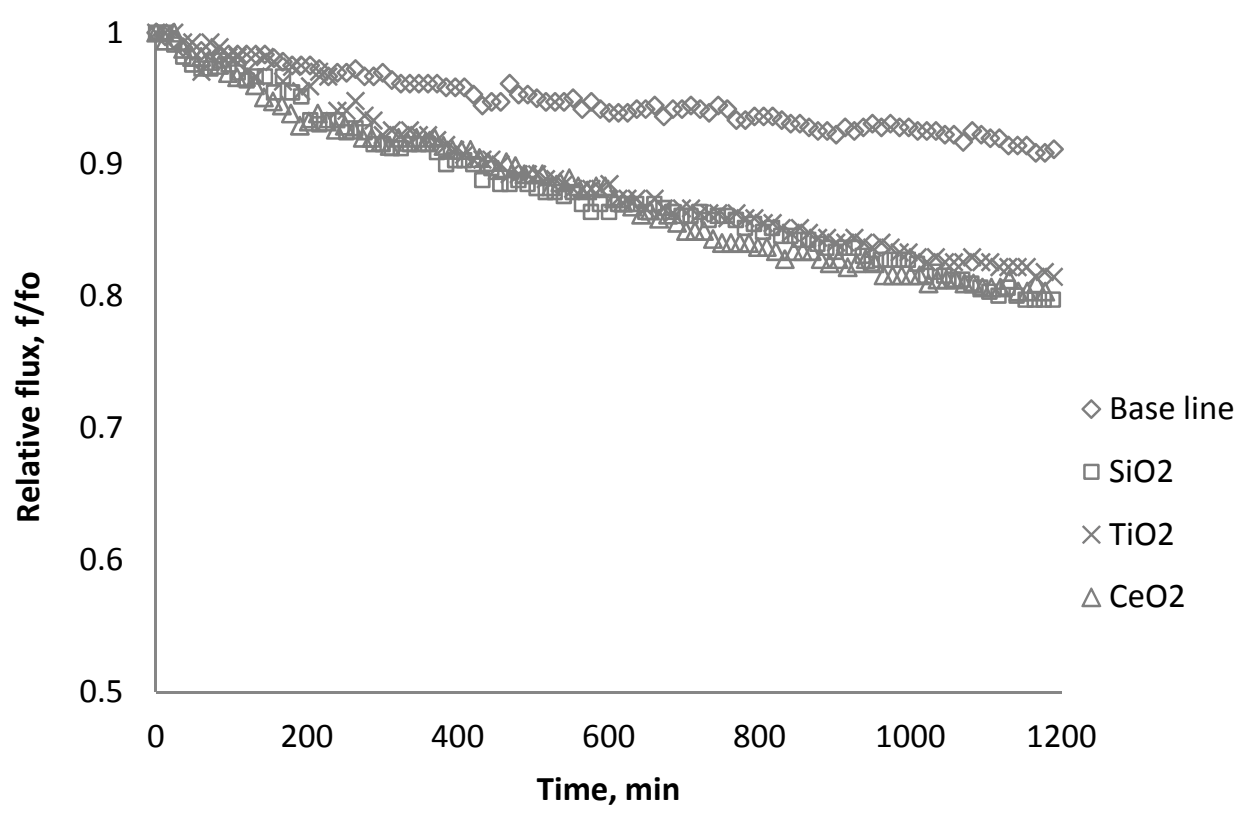

(a)

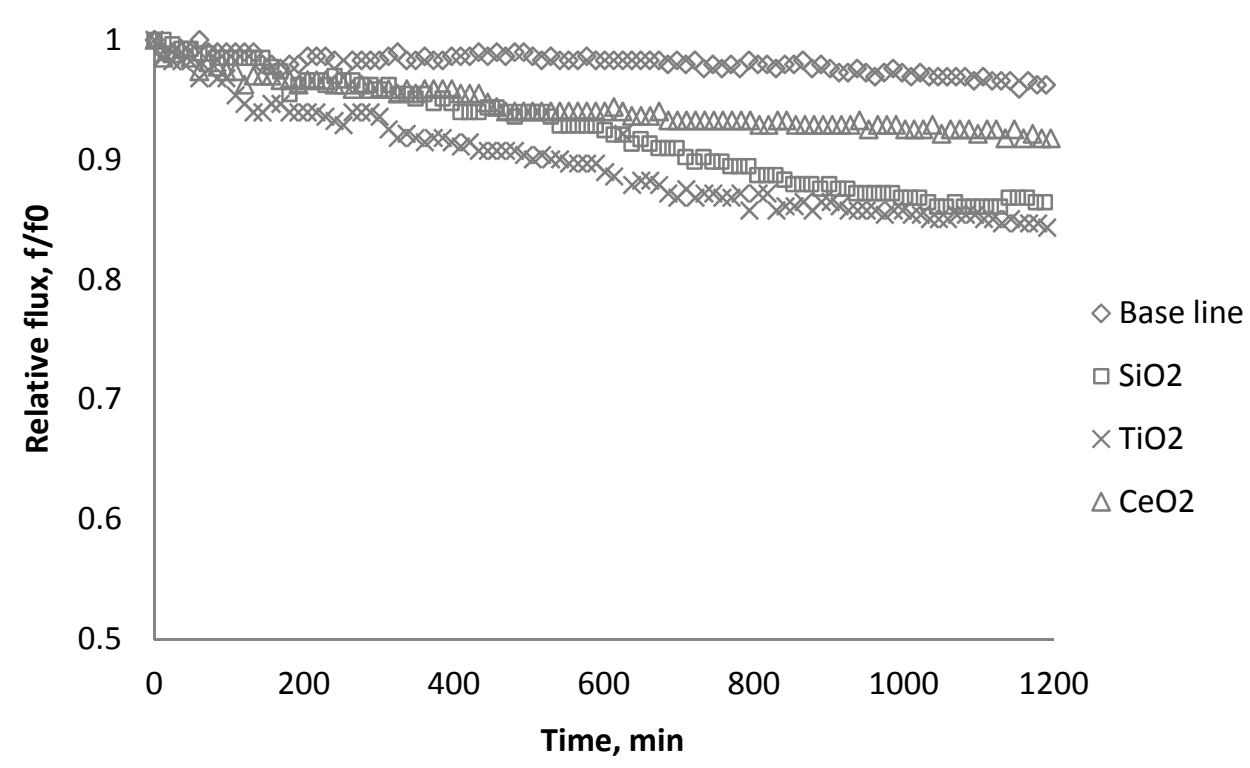

(b)

\subsection{Correlation of Membrane Surface Properties with Membrane Productivity}

In this section, membrane surface properties (contact angle and surface morphology) are investigated. The flux decline rate is shown to be related to these physical and chemical properties of membrane surface.

\subsubsection{Surface Morphology}

Membrane surface morphologies were measured using an AFM and are shown in Figure 19. The BW30 and XLE membranes depict a ridge-and-valley morphology, while the CK membranes show a 
smoother surface. The parameters obtained from AFM analysis are shown in Table 6. By comparing with the flux decline rate in Figures 5, 9, and 13, it can be concluded for the particles being tested, membranes with a higher mean roughness or root mean square (RMS) roughness suffer from flux decline at a higher speed, while membranes with smoother surfaces result in less flux decline. The mean value of the membrane surface was found to have no correlation to membrane productivity.

Figure 19. Atomic force microscopy (AFM) images of (a) DOW BW30 (RO); (b) DOW XLE (RO); (c) GE Osmonics CK (NF). Note the X and Y dimensions are both $10 \mu \mathrm{m}$ $(2 \mu \mathrm{m} / \mathrm{div})$, and the $\mathrm{Z}$ scale us $1 \mu \mathrm{m}(500 \mathrm{~nm} / \mathrm{div})$.

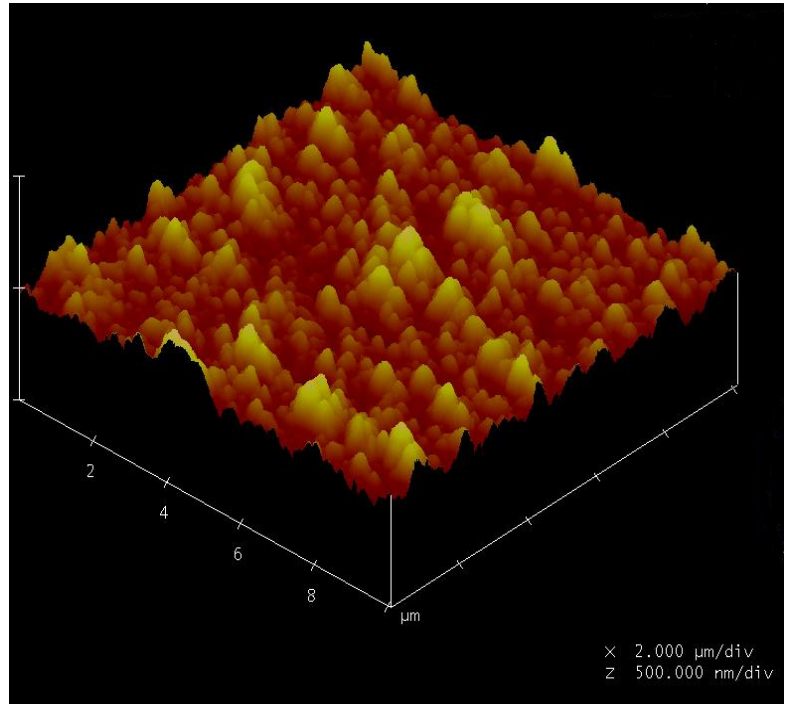

(a)

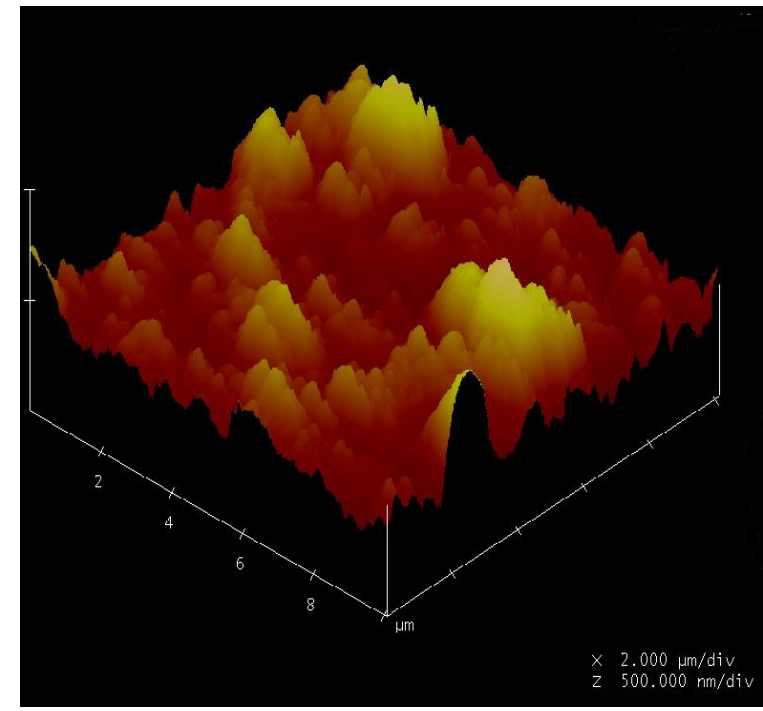

(b)

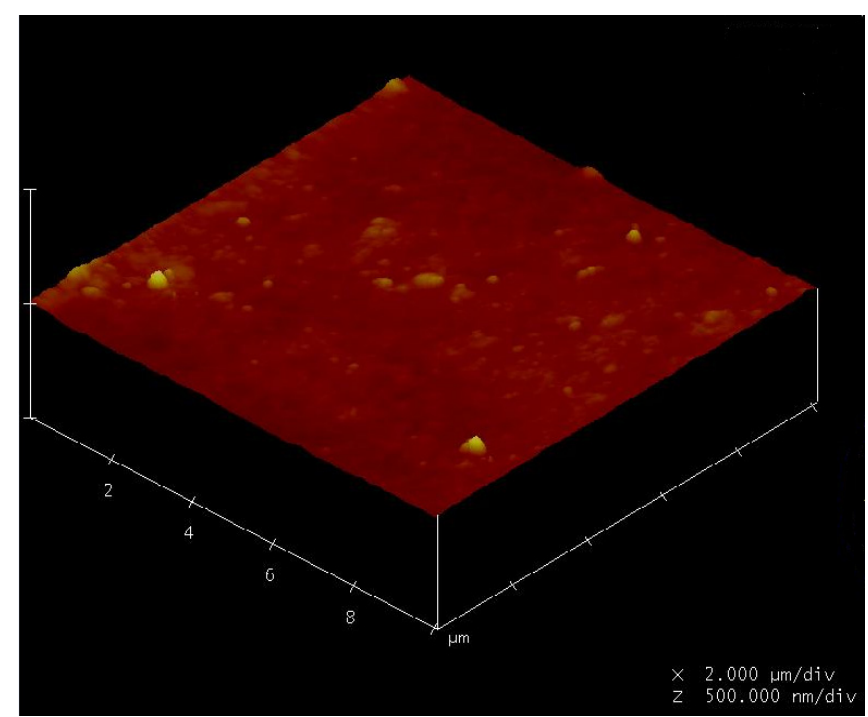

(c)

Table 6. AFM analysis of surface roughness.

\begin{tabular}{cccc}
\hline Membrane & Average roughness $(\mathbf{n m})$ & RMS * $(\mathbf{n m})$ & Mean $(\mathbf{n m})$ \\
\hline BW30 & 30 & 38.1 & 0 \\
XLE & 81.1 & 105.8 & 0.123 \\
CK & 5.1 & 6.6 & 0.018 \\
\hline
\end{tabular}

* RMS: root mean square. 


\subsubsection{Contact Angle}

Contact angles of clean membranes and membranes with particle deposition were measured and are shown in Table 7. There is no correlation between contact angle and flux decline rate. For each type of membranes, $\mathrm{SiO}_{2}$ and $\mathrm{CeO}_{2}$ increase the surface hydrophilicity, while $\mathrm{TiO}_{2}$ increases the surface hydrophilicity of the BW30 and XLE membranes and decreases the hydrophilicity of the CK membranes.

Table 7. Contact angle of clean and particle deposited membranes.

\begin{tabular}{ccc}
\hline Membrane & Condition & Contact angle \\
\hline \multirow{4}{*}{$\mathrm{BW} 30$} & $\mathrm{Clean}$ & 58.4 \\
& $\mathrm{SiO}_{2}$ & 48.8 \\
& $\mathrm{TiO}_{2}$ & 54.0 \\
& $\mathrm{CeO}_{2}$ & 51.5 \\
\hline \multirow{4}{*}{$\mathrm{XLE}$} & $\mathrm{Clean}$ & 61.5 \\
& $\mathrm{SiO}_{2}$ & 54.2 \\
& $\mathrm{TiO}_{2}$ & 53.2 \\
$\mathrm{CeO}_{2}$ & 46.4 \\
\hline \multirow{4}{*}{$\mathrm{CK}$} & $\mathrm{Clean}$ & 61.1 \\
& $\mathrm{SiO}_{2}$ & 58.8 \\
& $\mathrm{TiO}_{2}$ & 62.9 \\
& $\mathrm{CeO}_{2}$ & 54.5 \\
\hline
\end{tabular}

\section{Simulation of Cake Deposit Membrane Processes}

\subsection{Model Development}

For pressure-driven membrane processes, permeate water flux can be expressed by Equation (3), where the mass transfer coefficient $k_{w i}$ is a function of membrane thickness and described in Equation (4):

$$
\begin{gathered}
F_{w i}=k_{w i}\left(\Delta p_{i}-\Delta \pi_{i}\right)=\frac{Q_{p i}}{A_{i}} \\
k_{w i}=\theta_{w i} \delta_{i}
\end{gathered}
$$

where $\theta_{w i}$ is an empirical coefficient that correlates the mass transfer coefficient to the localized membrane thickness $\delta_{i}$. In the cake growth process, $\delta_{i}$ equals to the sum of clean membrane thickness $\left(\delta_{m}\right)$ and the cake thickness $\left(\delta_{c}\right)$.

The cake thickness, $\delta_{c}$, is a key unknown for the prediction of permeate flux during the experiment. The rate of cake layer growth is given by [25]:

$$
\frac{d \delta_{c i}}{d t}=k_{1} F_{w i}-k_{2} \delta_{c i}
$$

where $k_{1}$ and $k_{2}$ are constants. Equation (5) is based on the assumptions that the cake growth is proportional to the permeate flux and the particle back diffusion due to shear stresses increases by the membrane channel constriction as the cake grows. At the early stages of the experiment, when the 
membrane channel is not constricted by the cake grown and shear force is minimal. Equation (5) can be simplified as:

$$
\frac{d \delta_{c i}}{d t}=k_{1} F_{w i}
$$

The membrane channel is discretized to 500 uniform slices as described in the work of Fang and Duranceau [26]. The localized permeate flux can be determined by Equation (7):

$$
Q_{p i}=\frac{k_{w i}\left(\Delta p_{i}-k_{t} C_{i}\right)}{A_{j}}
$$

With consideration of pressure drop along the membrane channel, the localized trans-membrane pressure is determined by Equations (8) and (9):

$$
v_{i}=\frac{Q_{i}}{W H}
$$

where $W$ is the membrane element width and $H$ is the channel height. As feed flow travels in the membrane channel, transmembrane pressure decreases due the hydraulic head loss. The transmembrane pressure profile in the membrane channel can be described by Equation (9) [27]:

$$
\Delta P_{i}=\left(P_{f}-P_{p}\right)-\frac{12 k \mu v_{i} L}{n H^{2}}
$$

where $P_{f}$ and $P_{p}$ is the feed and permeate pressure, $k$ is the friction coefficient and is determined in the work of Fang and Duranceau [12], $\mu$ is the fluid viscosity, $L$ is the membrane channel length, and $n$ is the number of uniform slices for channel. Substituting Equation (7) into Equation (5), the cake thickness $\delta_{c i}$ at each time increment $t_{i}$ can be determined assuming initial thickness equals to zero. Because the localized $k_{w i}$ is affected by the localized thickness $\delta_{i}$, which is affected by the surface roughness. The cake thickness $\delta_{c i}$ is a localized variable determined by the permeate flux and surface roughness. The discretized forms of Equations (5) and (6) are:

$$
\begin{gathered}
\delta_{c(i+1)}=k_{1} F_{w i} d t+\left(1-k_{2} \delta_{c(i)} d t\right) \\
\delta_{c(i+1)}=k_{1} F_{w i} d t+\delta_{c(i)}
\end{gathered}
$$

\subsection{Numerical Representation of Membrane Surface Morphology}

With the surface parameters given in Table 5, the hypothetical clean membrane surfaces can be generated by MATLAB using the NORMRND and SMOOTHN functions [26]. Then the initial localized $k_{w i}$ and $F_{w i}$ can be calculated by Equations (3) and (4). Assuming the time interval $d t$ is $12 \mathrm{~min}$, the localized cake layer growth can be calculated at each time increment described by Equations (10) and (11). The overall cake thickness is the average of the cake thickness at each uniform slice. Two cases are considered depending on whether or not the back transport is significant.

\subsection{Effect of Surface Roughness on Overall Cake Growth Rate}

At an early stage of the experiment, when particle back transport can be negligible $\left(k_{1} F_{w i} \gg k_{2} \delta_{c i}\right)$, the permeate flux is controlled by the resistance of cake growth. The permeate flux decreases linearly due to the quick growth of cake. This condition is under the assumption that the rate 
of cake growth is much higher than the rate of particle back diffusion. By fitting the experimental data into Equation (11) using trial and error, $k_{1}$ can be solved. For different membranes tested with different particles, this condition only held until certain percentage of flux decline. Table 8 shows the percentage of flux decline when the back diffusion can be negligible.

Table 8. Percentage of flux decline when $k_{1} F_{w i} \gg k_{2} \delta_{c i}$ condition held.

\begin{tabular}{cccc}
\hline Membrane & $\mathbf{S i O}_{2}$ & $\mathbf{T i O}_{2}$ & $\mathbf{C e O}$ \\
\hline BW30 & $93 \%$ & $86 \%$ & $92 \%$ \\
XLE & $90 \%$ & $80 \%$ & $90 \%$ \\
CK & N/A & N/A & $97 \%$ \\
\hline
\end{tabular}

At the next stage of the experiment, the particle back diffusion term $\left(k_{2} \delta_{c i}\right)$ gains importance in comparison with the cake growth term $\left(k_{1} F_{w i}\right)$ in Equation (5). The permeate flux starts to decline at a lower rate compared with the previous stage. $k_{2}$ was also determined by fitting the simulated permeate flux to the experimental monitored flux data using trial and error. The ratio of $k_{1}$ over $k_{2}$ are used to evaluate the significance of the cake growth term $\left(k_{1} F_{w i}\right)$ and particle back diffusion term $\left(k_{2} \delta_{c i}\right)$ which is shown in Table 9.

Table 9. $k_{1}$ and $k_{2}$ values for different membranes tested with different particles.

\begin{tabular}{|c|c|c|c|c|c|c|}
\hline \multirow{2}{*}{ Membrane } & \multirow{2}{*}{ Particle } & Cake growth term & Particle back diffusion term & $k_{1}$ & \multirow{2}{*}{ RMS } & \multirow{2}{*}{$\begin{array}{c}\text { Applied } \\
\text { Pressure, psi }\end{array}$} \\
\hline & & $k_{1}$ & $k_{2}$ & $\overline{k_{2}}$ & & \\
\hline XLE & \multirow{3}{*}{$\mathrm{CeO}_{2}$} & 0.105 & 0.00055 & 191 & 105.8 & 130 \\
\hline BW30 & & 0.028 & 0.00012 & 233 & 38.1 & 260 \\
\hline CK & & 0.015 & 0.00009 & 167 & 6.6 & 230 \\
\hline XLE & \multirow{3}{*}{$\mathrm{SiO}_{2}$} & 0.029 & 0.00012 & 236 & 105.8 & 130 \\
\hline BW30 & & 0.020 & 0.00007 & 286 & 38.1 & 260 \\
\hline $\mathrm{CK}$ & & \multicolumn{2}{|c|}{ no flux decline, $\frac{d \delta_{c i}}{d t}=0$} & 0 & 6.6 & 230 \\
\hline XLE & \multirow{3}{*}{$\mathrm{TiO}_{2}$} & 0.060 & 0.00025 & 240 & 105.8 & 130 \\
\hline BW30 & & 0.023 & 0.00008 & 295 & 38.1 & 260 \\
\hline $\mathrm{CK}$ & & \multicolumn{2}{|c|}{ no flux decline, $\frac{d \delta_{c i}}{d t}=0$} & 0 & 6.6 & 230 \\
\hline
\end{tabular}

In a cake resistance model, a smaller ratio of $\frac{k_{1}}{k_{2}}$ indicates back diffusion $k_{2}$ is more significant and more particles remain in the bulk flow. The XLE and BW30 membranes have a higher $\frac{k_{1}}{k_{2}}$ value than the CK membranes, indicating the permeate flux is determined by the cake layer resistance and back diffusion is less significant. There is no observed flux decline using the $\mathrm{CK}$ membranes with $\mathrm{SiO}_{2}$ or $\mathrm{TiO}_{2}$ deposition, so Equation (5) can be approximated to zero and $\frac{k_{1}}{k_{2}}$ is determined by the following:

$$
\frac{k_{1}}{k_{2}} \approx \frac{\delta_{c i}}{F_{w i}}
$$

where $\delta_{c i}$ equals zero and $k_{2} \rightarrow \infty$. It is also noted that in most cases the XLE and BW30 membranes have a higher RMS value than the CK membranes, which corresponds to a higher $\frac{k_{1}}{k_{2}}$ ratio. In addition, when comparing the XLE and BW30 membranes, a higher applied pressure tends to produce more 
resistance for particle back diffusion, thereby the BW30 membranes have a higher $\frac{k_{1}}{k_{2}}$ ratio than the XLE membranes.

\subsection{Effect of Non-Homogeneous Surface on Particle Deposition Distribution}

A non-uniform permeability of membranes has been simulated using Equation (4). The growth of the deposit particles on the BW30 and XLE membranes has been studied. Using the empirical coefficients shown in Table 9, the localized cake thickness can be calculated by Equations (10) and (11). As an example, Figure 20 presents the cake thickness distribution through spatial and temporal variation for the BW30 and XLE membranes. At the beginning of the experiment, the distribution of cake thickness along the membrane channel is similar to the ridge-and-valley distribution on the clean membrane surface. By comparing the cake thickness distribution at the beginning and at the end of the experiment, the magnitude between ridge and valley is gradually diminished. This difference is demonstrated in Figure 20b in terms of $\Delta \delta_{0}$ as the cake thickness difference between the ridge and valley at the beginning and $\Delta \delta_{\mathrm{m}}$ as in the end of the experiment. This observation indicates that the valley areas of the membranes are filled up by particles in a higher rate than the ridges which is one of the primary reasons for flux decline.

Figure 20. Simulation of cake thickness growth along the membrane channel during the experiments: (a) BW30 RO; (b) XLE RO. Noted that feed stream contained $135 \mathrm{mg} / \mathrm{L} \mathrm{SiO}_{2}$ and ionic strength was maintained as $0.05 \mathrm{M} \mathrm{NaCl}$.

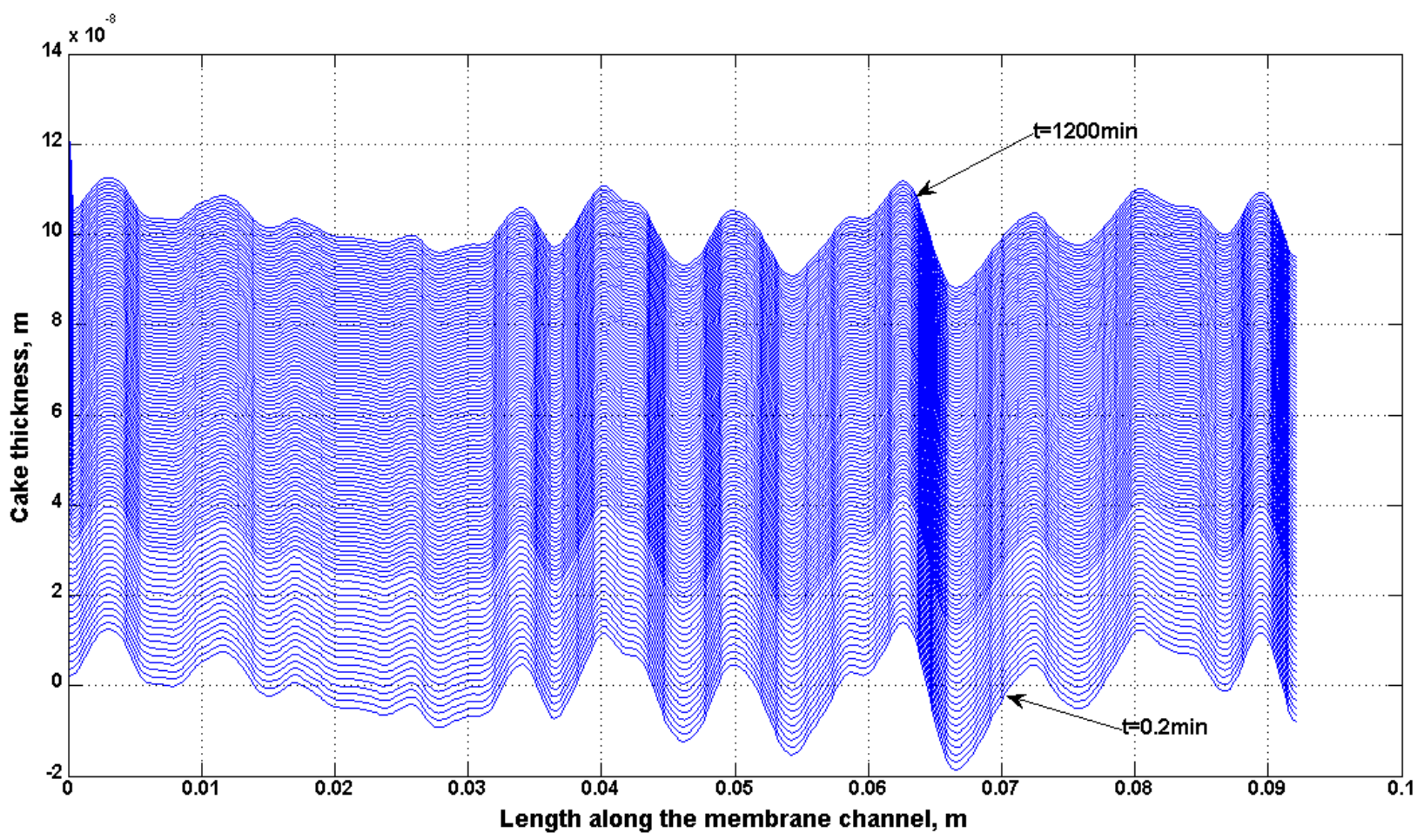

(a) 
Figure 20. Cont.

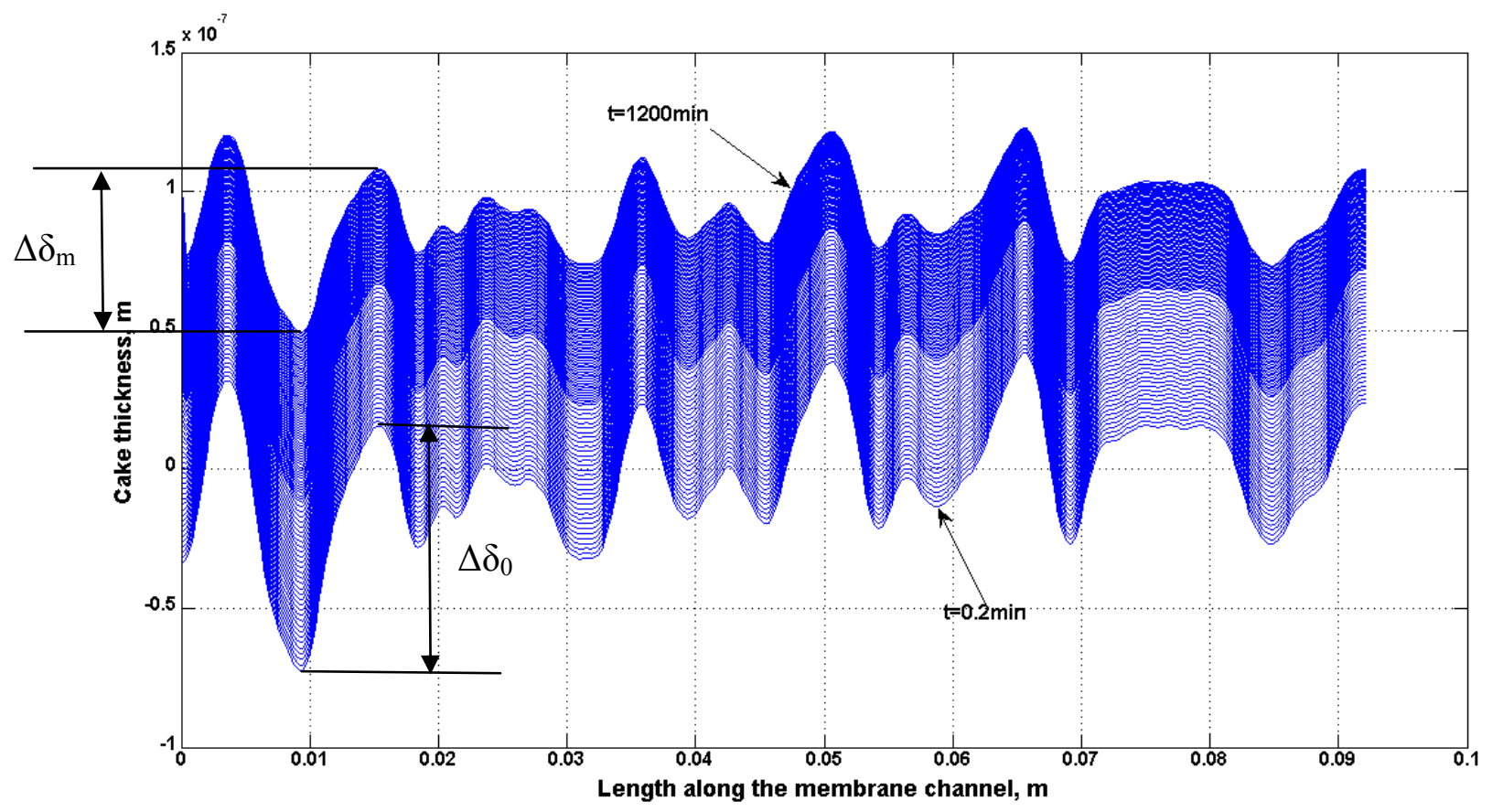

(b)

\subsection{Comparison of Simulation and Experimental Results}

Using $k_{1}$ and $k_{2}$ from Table 9, the fitted lines and the experimental data for BW30 and XLE membranes are plotted from Figures 21-26. The solid line represents the simulation fit and the markers are the monitored data. In the first stage, the cake growth rate is proportional to the flux decline rate and the back diffusion is minimized. In the second stage, the cake growth rate decreases due to the back diffusion of particles and the flux curve flattens slightly. The fit lines appear to be in good agreement with the experimental data, indicating the estimated $k_{1}$ and $k_{2}$ values are valid.

Figure 21. Permeate flux over time with $135 \mathrm{mg} / \mathrm{L} \mathrm{SiO}_{2}$ in the feed stream tested on BW30 membrane.

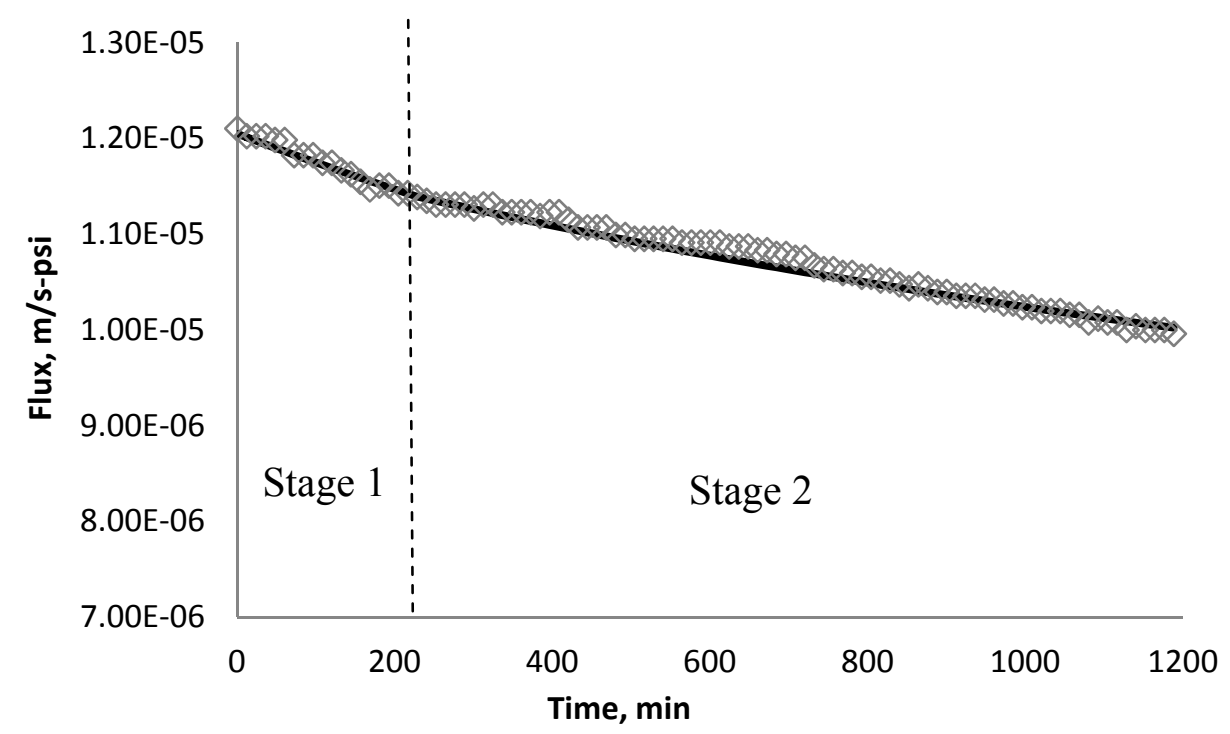


Figure 22. Permeate flux over time with $135 \mathrm{mg} / \mathrm{L} \mathrm{TiO}_{2}$ in the feed stream tested on BW30 membrane.

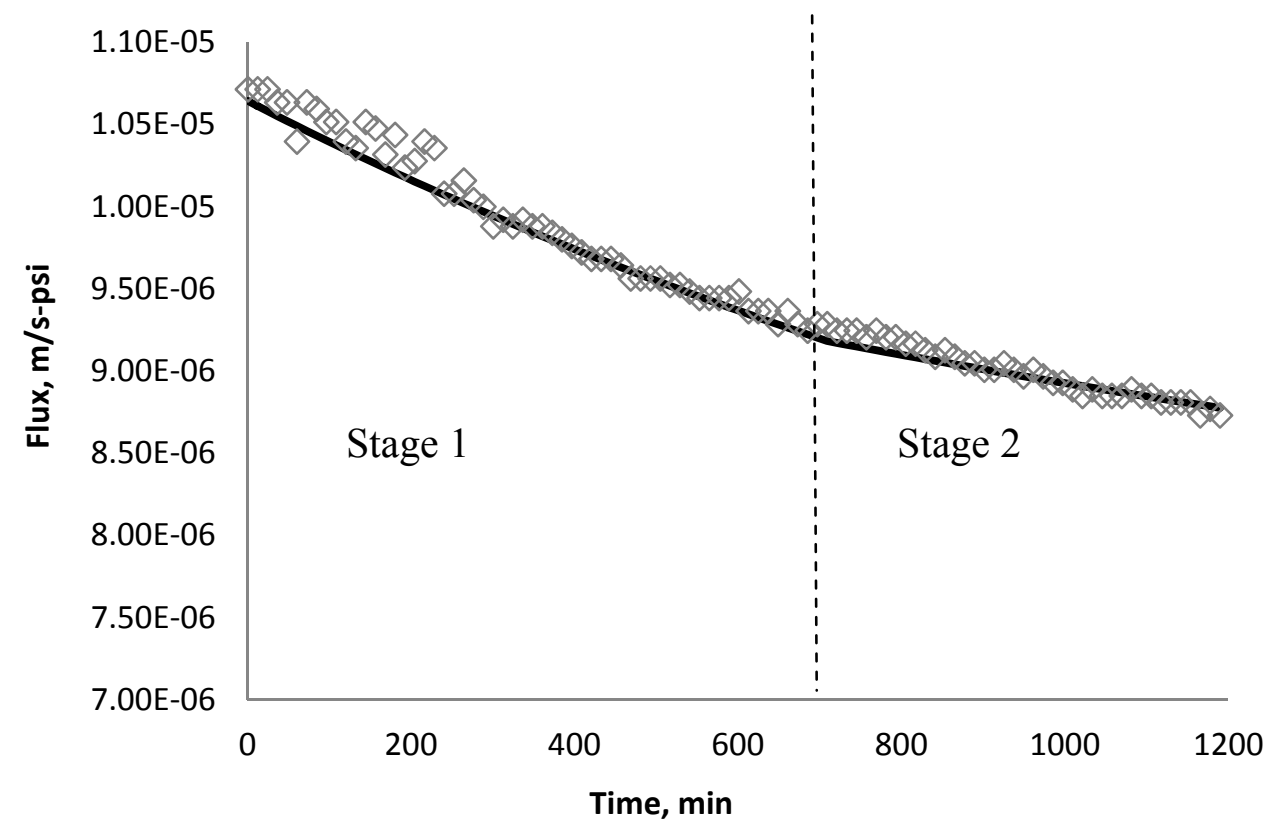

Figure 23. Permeate flux over time with $135 \mathrm{mg} / \mathrm{L} \mathrm{CeO}_{2}$ in the feed stream tested on BW30 membrane.

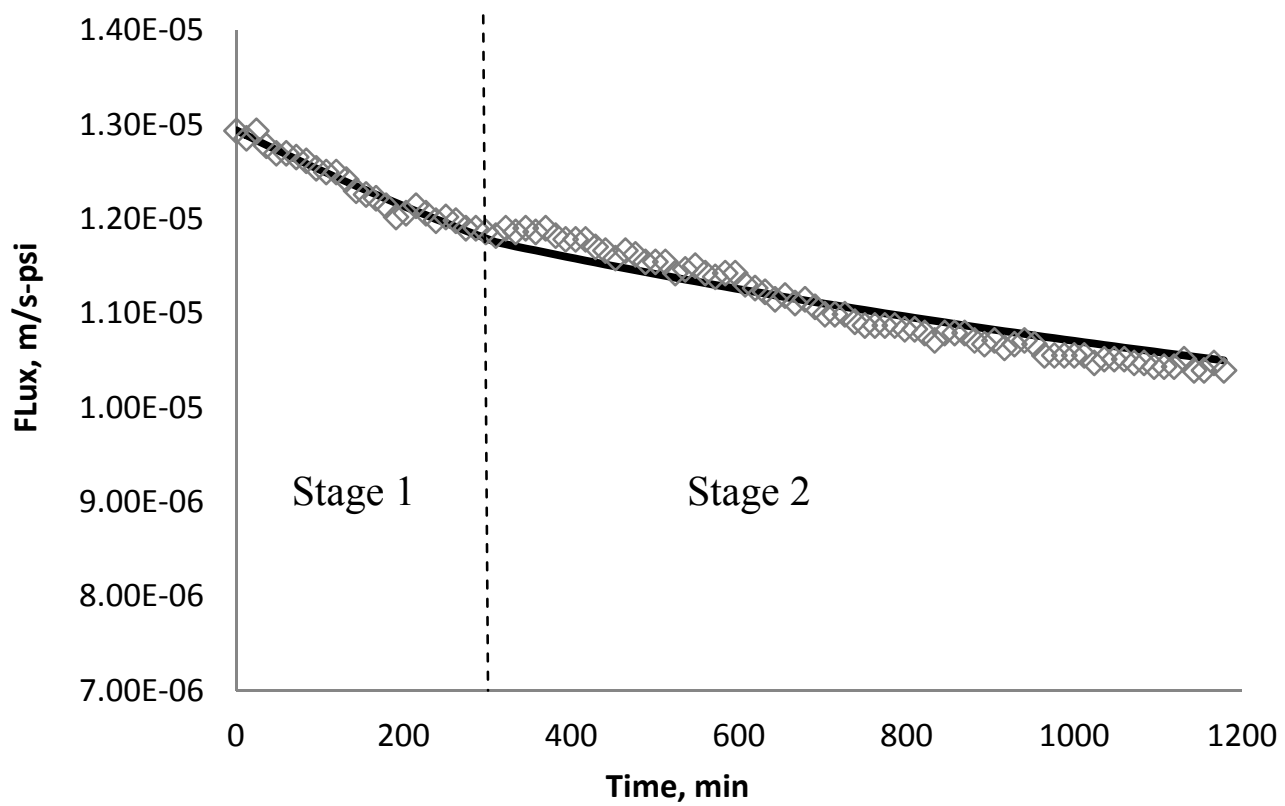


Figure 24. Permeate flux over time with $135 \mathrm{mg} / \mathrm{L} \mathrm{SiO}_{2}$ in the feed stream tested on XLE membrane.

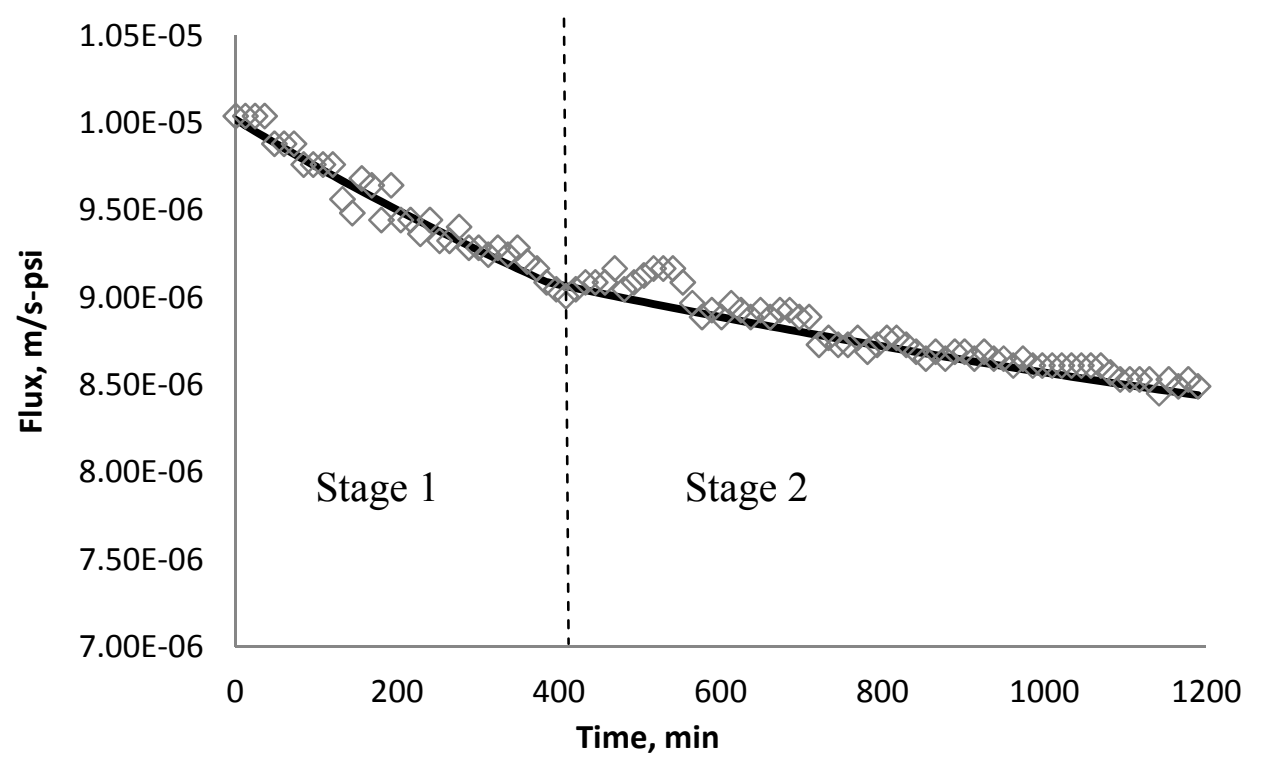

Figure 25. Permeate flux over time with $135 \mathrm{mg} / \mathrm{L} \mathrm{TiO}_{2}$ in the feed stream tested on XLE membrane.

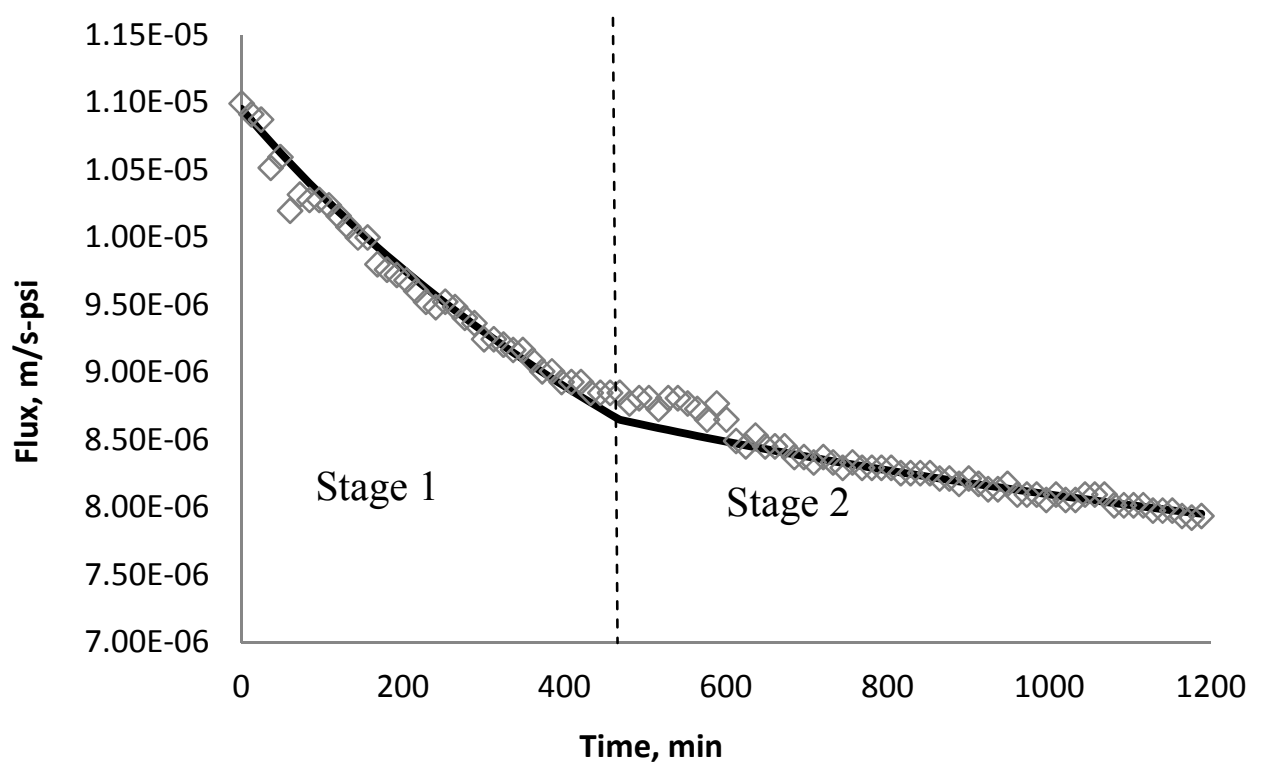


Figure 26. Permeate flux over time with $135 \mathrm{mg} / \mathrm{L} \mathrm{CeO}_{2}$ in the feed stream tested on XLE membrane.

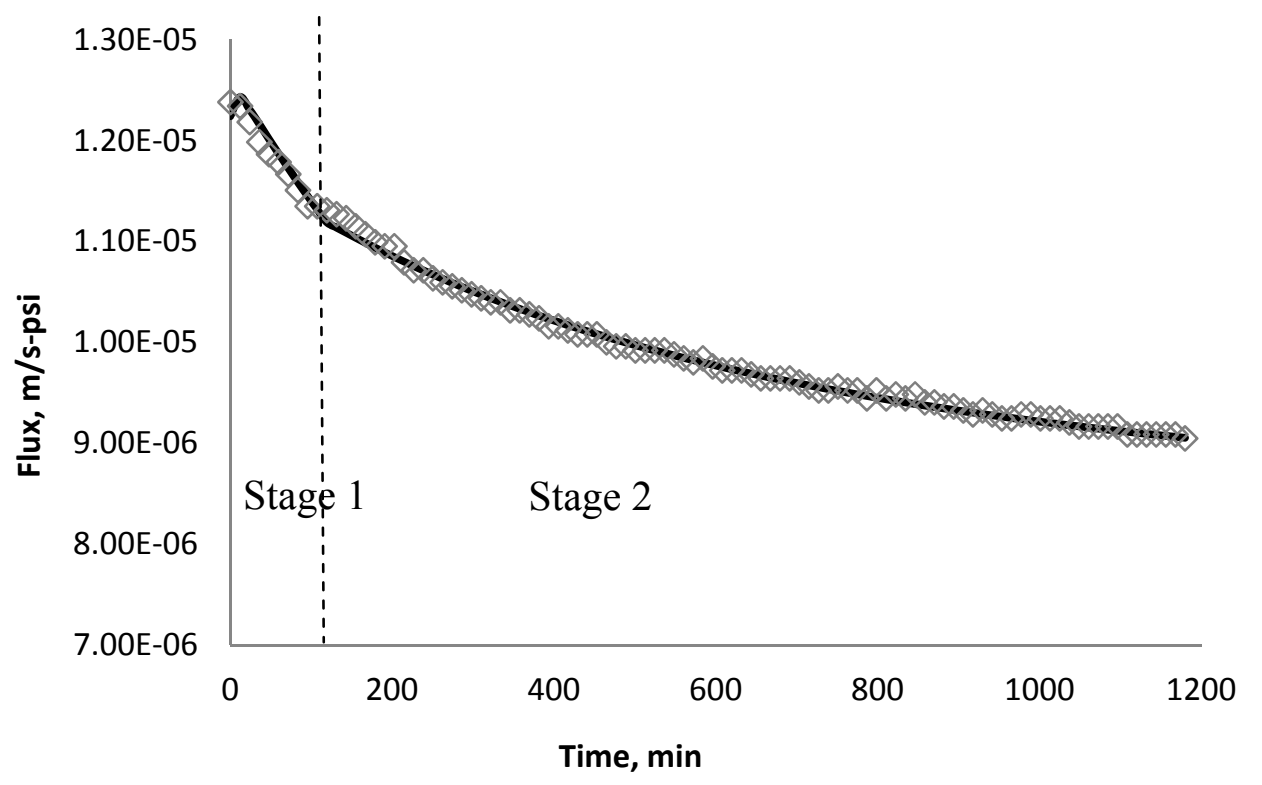

\section{Conclusions}

In this work, bench scale membrane productivity experiments were conducted to investigate the role of membrane surface properties on the productivity of RO and NF. Three different nanoparticles were injected into the feed stream and the intensity of flux decline was characterized in terms of relative flux $\left(\mathrm{f} / \mathrm{f}_{0}\right)$. In the three cases evaluated, the intensity of flux decline was influenced by membrane surface morphology. The AFM analysis reveals that the higher flux decline rate of the XLE and BW30 membranes compared to that of the $\mathrm{CK}$ membranes is due to the inherent ridge-and-valley morphology of the XLE and BW30 membranes. This unique morphology increases the surface roughness, leading to particles accumulation in the valleys, and causing more flux decline than in smoother membranes. Simulation results also indicate back diffusion of deposit particles is more severe on the smooth membranes than on the rough membranes. The valley areas of membranes have the ability to capture the particles and protect them from back diffusion.

Extended productivity experiments were conducted using the BW30 membranes to compare the effect of different particles on diluted seawater versus laboratory controlled water. When supplying the membranes with laboratory controlled water, the flux decline at a similar rate regardless of particle type. But when supplying the membranes with a pretreated yet diluted seawater supply, $\mathrm{CeO}_{2}$ results the least flux decline compared to the other particles.

\section{Conflicts of Interest}

The authors declare no conflict of interest. 


\section{References}

1. Liikanen, R.; Yli-Kuivila, J.; Laukkanen, R. Efficiency of various chemical cleanings for nanofiltration membrane fouled by conventionally-treated surface water. J. Membr. Sci. 2002, $195,265-276$.

2. Shaalan, H.F. Development of fouling control strategies pertinent to nanofiltration membranes. Desalination 2002, 153, 125-131.

3. Kim, S.; Kwak, S.; Sohn, B.; Park, T. Design of $\mathrm{TiO}_{2}$ nanoparticle self-assembled aromatic polyamide thin-film-composite (TFC) membrane as an approach to solve biofouling problem. J. Membr. Sci. 2003, 211, 157-165.

4. Belfort, G.; Davis, R.; Zydney, A. The behavior of suspensions and macromolecular solutions in crossflow microfiltration. J. Membr. Sci. 1994, 96, 1-58.

5. Boussu, K.; Brlpaire, A.; Volodin, A.; Haesendonck, C.V.; van der Meeren, P.; Vandecasteele, C.; van der Bruggen, B. Influence of membrane and colloid characteristics on fouling of nanofiltration membranes. J. Membr. Sci. 2007, 289, 220-230.

6. Norberg, D.; Hong, S.; Taylor, J.; Zhao, Y. Surface characterization and performance evaluation of commercial fouling resistant low-pressure RO membranes. Desalination 2007, 202, 45-52.

7. Zhu, X.; Elimelech, M. Colloidal fouling of reverse osmosis membranes: Measurements and fouling mechanism. Environ. Sci. Technol. 1997, 31, 3654-3662.

8. Tarabara, V.; Koyuncu, I.; Wiesner, M. Effect of hydrodynamics and solution ionic strength on permeate flux in cross-flow filtration: Direct experimental observation of filter cake cross-sections. J. Membr. Sci. 2004, 241, 65-78.

9. Zhang, M.; Song, L. Mechanisms and parameters affecting flux decline in cross-flow microfiltration and ultrafiltration of colloids. Environ. Sci. Technol. 2004, 34, 3767-3773.

10. Lee, S.; Cho, J.; Elimelech, M. Combined influence of natural organic matter and colloid particles on nanofiltration membrane fouling. J. Membr. Sci. 2005, 262, 27-41.

11. Singh, G.; Song, L. Quantifying the effect of ionic strength on colloidal fouling potential in membrane filtration. J. Colloid Interface Sci. 2005, 284, 630-638.

12. Lee, S.; Cho, J.; Elimelech, M. Influence of colloidal fouling and feed water recovery on salt rejection of reverse osmosis and nanofiltration membranes. Desalination 2004, 160, 1-12.

13. Vrijenhoek, E.M.; Hong, S.; Elimelech, M. Influence of membrane surface properties on initial rate of colloidal fouling of reverse osmosis and nanofiltration membranes. J. Membr. Sci. 2001, $188,115-128$.

14. Madaeni, S.; Ghaemi, N. Characterization of self-cleaning RO membranes coated with $\mathrm{TiO}_{2}$ particles under UV irradiation. J. Membr. Sci. 2007, 303, 221-233.

15. Bae, T.-H.; Tak, T.-M.T. Preparation of $\mathrm{TiO}_{2}$ self-assembled polymeric nanocomposite membranes and examination of their fouling mitigation effects in a membrane bioreactor system. J. Membr. Sci. 2005, 266, 1-5.

16. Cao, X.; Ma, J.; Shi, X.; Ren, Z. Effect of $\mathrm{TiO}_{2}$ nanoparticle size on the performance of PVDF membrane. Appl. Surf. Sci. 2006, 253, 2003-2010. 
17. Razmjou, A.; Mansouri, J.; Chen, V. The effects of mechanical and chemical modification of $\mathrm{TiO}_{2}$ nanoparticles on the surface chemistry, structure and fouling performance of PES ultrafiltration membranes. J. Membr. Sci. 2011, 378, 73-84.

18. Crittenden, J.C.; Trussell, R.R.; Hand, D.W. Water Treatment Principles and Design; Jonh Wiley \& Sons. Inc.: Hoboken, NJ, USA, 2012.

19. Hoek, E.M.; Elimelech, M. Cake-enhanced concentration polarization: A new fouling mechamism for salt-rejecting membranes. Environ. Sci. Technol. 2003, 37, 5581-5588.

20. Mohammadi, T.; Kazeminoghadam, M.; Saadabadi, M. Modeling of membrane fouling and flux decline in reverse osmosis during separation of oil in water emulasions. Desalination 2003, 157, 369-375.

21. Lim, A.; Bai, R. Membrane fouling and cleaning in microfiltration of activated sludge wastewater. J. Membr. Sci. 2003, 216, 279-290.

22. Bolton, G.; LaCasse, D.; Kuriyel, R. Combined models of membranes fouling: Development and application to microfiltration and ultrafiltration of biological fluids. J. Membr. Sci. 2006, 277, 75-84.

23. Sioutopoulos, S.G.; Yiantsios, D.G.; Karabelas, A.J. Relation between fouling characteristics of RO and UF membranes in experiments with colloidal organic and inorganic species. J. Membr. Sci. 2010, 350, 62-82.

24. Elimelech, M.; Zhu, X.; Childress, A.E.; Hong, S. Role of membrane surface morphology in colloidal fouling of cellulose acetate and composite aromatic polyamide reverse osmosis membranes. J. Membr. Sci. 1997, 127, 101-109.

25. Wiesner, M.; Veerapaneni, S.; Brejchova, D. Improvements in Membrane Microfiltration Using Coagulation Pretreatment. In Chemical Water and Wastewater Treatment; Hahn, H., Klute, R., Eds.; Springer Verlag: Berlin, Germany, 1992.

26. Fang, Y.; Duranceau, S.J. Comparison of Non-Homogeneous and Homogeneous Mass Transfer in Reverse Osmosis Membrane Processes. Desalin. Water Treat. 2013, in press.

27. Bouchard, C.R.; Carreau, P.J.; Matsuura, T.; Sourirajan, S. Modeling of ultrafiltration: Prediction of concentration polarization effect. J. Membr. Sci. 1994, 97, 215-229.

(C) 2013 by the authors; licensee MDPI, Basel, Switzerland. This article is an open access article distributed under the terms and conditions of the Creative Commons Attribution license (http://creativecommons.org/licenses/by/3.0/). 